\title{
La formación universitaria sobre Publicidad y Relaciones Públicas en España tras 50 años de historia: qué y cómo enseñamos
}

\section{University education in Advertising and Public Relations in Spain after 50 years: what and how we teach}

\author{
Antonio-José Baladrón-Pazos; Beatriz Correyero-Ruiz; Benjamín Manchado-Pérez
}

Cómo citar este artículo:

Baladrón-Pazos, Antonio-José; Correyero-Ruiz, Beatriz; Manchado-Pérez, Benjamín (2022). "La formación universitaria sobre Publicidad y Relaciones Públicas en España tras 50 años de historia: qué y cómo enseñamos". Profesional de la información, v. 31, n. 1, e310113.

https://doi.org/10.3145/epi.2022.ene.13

Artículo recibido el 27-06-2021 Aceptación definitiva: 14-12-2021

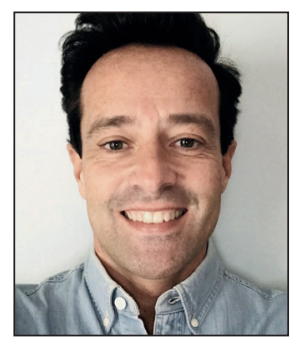

Antonio-José Baladrón-Pazos https://orcid.org/0000-0001-7870-2545

Universidad Rey Juan Carlos

Edificio Departamental I

Camino del molino, 5

29843 Fuenlabrada (Madrid), España

antonio.baladron@urjc.es

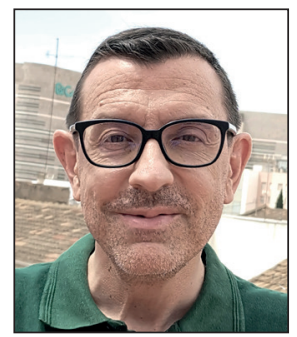

Benjamín Manchado-Pérez

https://orcid.org/0000-0001-9176-3182

Universidad Complutense de Madrid

Facultad de Ciencias Económicas y

Empresariales

Campus de Somosaguas, $\mathrm{s} / \mathrm{n}$

28223 Pozuelo de Alarcón (Madrid), España

benjaman@ucm.es

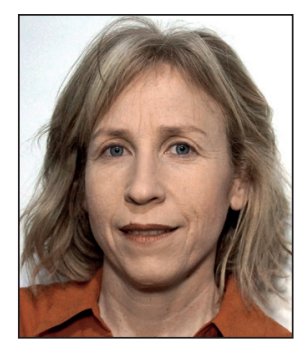

Beatriz Correyero-Ruiz $\square$

https://orcid.org/0000-0003-0069-8448

Universidad Católica de Murcia

Facultad de Ciencias Sociales y de la

Comunicación

Campus de los Jerónimos, s/n

30107 Guadalupe (Murcia), España

bcorreyero@ucam.edu

\section{Resumen}

Tras cumplirse 50 años de la incorporación de los estudios de Comunicación a la universidad española, en este artículo se recogen los resultados de una investigación descriptiva acerca de la formación universitaria presencial de grado sobre Publicidad y Relaciones Públicas en España, con el doble objetivo de conocer cómo se caracteriza formalmente, y qué y cómo se enseña. Se recopilaron 1.815 guías docentes correspondientes a 10.224 créditos ECTS de las 41 titulaciones de grado que se imparten en 38 centros de formación, tras lo cual se procedió al análisis estadístico de los datos recogidos en las fichas de codificación, que se agruparon en 57 variables. Se concluye, por una parte, el mayoritario peso de la iniciativa privada en la formación universitaria de esta área, y la escasa internacionalización en cuanto al testimonial uso del inglés en la docencia. Respecto a los campos temáticos abordados, se constata su carácter generalista, con un porcentaje destacado de contenidos transversales de Comunicación y de otras áreas no comunicológicas, así como un claro predominio de la formación publicitaria sobre la de Relaciones Públicas, siendo los campos especializados más relevantes la creatividad, por un lado, y la Publicidad y el Marketing Digital, por otro. En la docencia se observa un mayor peso de las actividades de tipo práctico frente a la tradicional clase teórica o magistral. La evaluación del estudiante también está más basada en prácticas, más que en pruebas escritas o exámenes sobre conocimientos teóricos. Estos últimos aspectos corroboran el poso que ha dejado el Plan Bolonia y las normativas a él debidas, aunque no se haya alcanzado plenamente la renovación metodológica que preconizaba. 


\title{
Palabras clave
}

Publicidad; Relaciones Públicas; Enseñanza universitaria; Docencia; Universidad; Formación; Educación; España; Comunicación; Planes de estudio; Asignaturas; Guías docentes; EEES.

\begin{abstract}
Fifty years after the introduction of Communication studies into Spanish universities, this article presents the results of a descriptive investigation of on-campus university education in Advertising and Public Relations in Spain, with the dual aim of gaining an understanding of how it is formally, and what and how it is taught. A total of 1,815 teaching guides amounting to 10,224 ECTS credits were compiled for the 41 degree courses taught in 38 training centers. The data collected in coding sheets were statistically analyzed and grouped into 57 variables. The results highlight the majority of private initiatives in university education in this area, and the scarce internationalization with only token use of English in teaching. We observe a significant relative presence of cross-cutting content between Communication and other areas, as well as a clear predominance of Advertising training over Public Relations. The most relevant specialized areas are creativity, and advertising and digital marketing. In teaching, a greater weight of practical activities is observed compared with traditional theoretical or master classes. The evaluation of students is also more based on practical work rather than written tests or examinations on theoretical knowledge. These latter aspects confirm the footprint left by the Bologna Plan and the regulations it drove, although the methodological renovation it advocated has yet to be fully achieved.
\end{abstract}

\section{Keywords}

Advertising; Public Relations; University training programs; Teaching; University; Training; Education; Spain; Communication; Curricula; Subjects; Teaching guides; EHEA; European Higher Education Area.

\section{Introducción}

\subsection{Antecedentes de la formación sobre Publicidad y Relaciones Públicas}

La formación sobre Publicidad y Relaciones Públicas en España cuenta con una trayectoria no muy extensa desde el punto de vista histórico. Fue sobre todo a principios del siglo XX, con Pere Prat Gaballí (1885-1962) como figura fundamental según destacan varios autores (Barjau-Rico, 2002; Eguizábal-Maza, 1998; Quintas-Froufe, 2011), cuando se consolidaron los primeros acercamientos teóricos a la Publicidad y se sentaron las bases de la formación publicitaria. Sin embargo, ya con anterioridad, al amparo de las primeras agencias creadas desde finales del siglo anterior XIX, se habían desarrollado algunas acciones formativas en esa área. Precisamente Prat Gaballí fue quien impartió las primeras lecciones sobre Publicidad en la Cámara de Comercio y Navegación de Barcelona; quien fundó Comercio, la primera revista de temas publicitarios; quien publicó la monografía pionera Una nueva técnica. La publicidad científica (Prat-Gaballí, 1917); y quien en 1922 creó la Asociación de Profesionales de la Publicidad, asociación que a partir de 1928 dio lugar al Publi-Club catalán, integrado por profesionales que cumplieron un papel fundamental en el impulso a la docencia publicitaria.

El primer centro docente dedicado a la Publicidad se creó en 1960, la Escuela de Publicidad del Centro Español de Nuevas Profesiones, una institución privada que intentaba dar respuesta a la necesidad de formación de los nuevos profesionales del sector, en expansión gracias al desarrollo económico y la apertura internacional del régimen franquista. Con la aprobación del Estatuto de la Publicidad, mediante la Ley 61/1964 de 11 de junio (España, 1964), se constituyó un organismo público encargado de "proporcionar las enseñanzas que habiliten para el ejercicio profesional de la publicidad en sus diversas especialidades" (artículo 20), lo cual supuso un hito clave en la docencia publicitaria. Así, fue en ese mismo año cuando nació el primer centro público y oficial de formación publicitaria, la Escuela Oficial de Publicidad en Madrid, creándose en 1968 su sección en Barcelona. Por tanto, esto tuvo lugar dos décadas después de la primera escuela oficial de Periodismo, de 1941 (Ramírez-Alvarado; Clemente-Mediavilla, 2020). Desde 1964 el Instituto Oficial de Publicidad veló por la armonización de los programas formativos de los centros existentes, conviviendo la iniciativa pública con la privada: el mencionado Centro Español de Nuevas Profesiones junto a otros como el Instituto Castellano de Nuevas Profesiones de Valladolid; la Escuela de Publicidad Pax de Valencia; el Centro Técnico de Nuevas Profesiones de Salamanca, el Centro de Instrucción Comercial e Industrial y el Centro de Estudios Turísticos Sol (ambos de Madrid); la Escuela de Publicidad de Zaragoza; la Escuela de Publicidad de Santa Cruz de Tenerife y su homónima de Las Palmas de Gran Canaria; o el Centro Docente San Luis Gonzaga de Palma de Mallorca.

La trayectoria académica de las Relaciones Públicas en España también es bastante reciente, manifestándose en la segunda mitad del siglo XX (Noguero-Grau, 1994). Algunos autores destacan su imbricación con el Periodismo: por ejemplo, García-Nieto y Davara-Rodríguez hacen referencia a "una común historia en su periplo hacia la formación superior" (García-Nieto; Davara-Rodríguez, 2020, p. 65). Otros, abundando en una comprensión multidisciplinar de las Relaciones Públicas, ligan sus primeros pasos profesionales en España a otros campos como el publicitario:

"las ingentes labores de los adelantados Prat Gaballí y García Ruescas [...] desarrollaron, antes del propio concepto, las Relaciones Públicas en España principalmente desde el campo de la Publicidad y desde el de la Propaganda" (Caldevilla-Domínguez; Barrientos-Báez; Fombona-Cadavieco, 2020, p. 22). 
Sea como fuere, al tiempo que en el continente europeo intelectuales como el francés Lucien Matrat contribuía de manera decisiva a la construcción teórica de las Relaciones Públicas y fundaba la primera asociación profesional europea (Xifra, 2006), en España se asiste a algunos momentos importantes en el asentamiento profesional de esta actividad profesional: en 1960 nació la primera agencia como tal de Relaciones Públicas y en 1961 se creó en Madrid la Asociación Técnica de Relaciones Públicas (ATRP).

Respecto a su consolidación como disciplina, es en 1957 cuando Juan Beneyto hizo la primera referencia académica a las Relaciones Públicas en el libro Mass communications: Un panorama de los medios de comunicación en la sociedad moderna (Beneyto-Pérez, 1957), si bien ya había anticipado sus reflexiones en un seminario que impartió en 1954. Como recogen Almansa-Martínez y Moreno-Cabanillas (2021) en la obra de Romero-Rodríguez y Fernández-Camacho (2021), otros hitos fundamentales son la publicación en 1957 del primer libro específico sobre la materia y la creación, en 1962, de la revista Relaciones Públicas. La primera escuela española de esta disciplina reconocida oficialmente fue la Escuela Superior de Relaciones Públicas de Barcelona, nacida en 1968 y reconocida en 1969 como centro adscrito a la Universidad de Barcelona. En ella, los estudiantes obtenían los títulos de Técnico en Relaciones Públicas y Graduado Superior de Relaciones Públicas. Poco tiempo antes, en 1967, los nuevos planes de estudio aprobados en la Escuela Oficial de Periodismo de Madrid ya incluían en tercer curso la asignatura "Fundamentos de Psicología y teoría y técnica de las Relaciones Públicas", a cargo de Juan Beneyto, primera referencia a las Relaciones Públicas en planes académicos. Además, esa misma asignatura explicada por el mismo profesor y con una denominación diferente también se incluía en 1969 en el plan de estudios de la Escuela de Periodismo de la Iglesia (García-Nieto; Davara-Rodríguez, 2020).

La necesidad de reforzar los estudios de Relaciones Públicas en España y dotarlos de una formación superior ya se había manifestado en el I Congreso de Relaciones Públicas, que tuvo lugar en el año 1966. Pero un paso relevante tuvo lugar en 1969, cuando se celebró la Primera Asamblea Nacional de Relaciones Públicas, cuyas conclusiones, entre otras referidas a la regulación de estas enseñanzas, fueron posteriormente entregadas a instancias gubernamentales en representación de las tres asociaciones que existían de esta disciplina tras la desaparición de la ATRP: el Centro Español de Relaciones Públicas de Madrid; la Agrupación Española de Relaciones Públicas de Barcelona y el Centro Mallorquín de Relaciones Públicas.

\subsection{Universidad y formación sobre Publicidad y Relaciones Públicas}

Decisivo para asentar la formación en el área de Publicidad y Relaciones Públicas fue la incorporación a la universidad española de los estudios de Comunicación, como señala Vigil-y-Vázquez (1987). El Decreto 2070/1971 (España, 1971), de 13 de agosto, por el que se regulan los estudios de Periodismo y demás medios de comunicación social en la universidad, estableció, en cumplimiento de lo recogido en la franquista Ley general de educación y financiamiento de la reforma educativa (España, 1970), las bases para la creación de las Facultades de Ciencias de la Información y para que en ellas se impartiesen

"tres secciones o ramas que se denominarán (...) de Periodismo, de Ciencias de la Imagen Visual y Auditiva, y de Publicidad" (artículo 2).

En el curso 1971-1972 fueron pioneras en la constitución de estas nuevas Facultades la Universidad Complutense de Madrid y la Universitat Autònoma de Barcelona, principales núcleos urbanos del país, a las que se sumó pocos meses después la Universidad de Navarra, si bien ofertó estudios de Publicidad y Relaciones Públicas con posterioridad. Como consecuencia, las Escuelas Oficiales de Periodismo o de Publicidad cerraron sus puertas en 1975 tras graduarse las últimas promociones, si bien continuó operativa la Escuela Superior de Relaciones Públicas, adscrita a la Universitat de Barcelona. La implantación de los nuevos planes de formación fue acompañada de problemas tanto de infraestructuras como de plantillas docentes. En cuanto a esto último, en aquel momento se acusaba la inexistencia de investigadores especializados en el área, por lo que se daba una gran multidisciplinariedad, proviniendo muchos de ellos de otras áreas como Derecho o Letras, tanto en el caso de la docencia sobre Publicidad como sobre Relaciones Públicas. En el caso de Publicidad, la Escuela Oficial aportó expertos en la materia que se incorporaron a las universidades, mientras que la Escuela Superior de Relaciones Públicas no contribuyó en igual grado debido a que ya estaba integrada como centro adscrito en la estructura universitaria y por tanto no se llegó a clausurar tras la apertura de las facultades universitarias, como sí sucedió en el caso de la escuela publicitaria.

Con el paso de los años, varias universidades del territorio español apostaron por ofertar la entonces licenciatura en Publicidad y Relaciones Públicas. Así, como relata Rey-Fuentes (2009), en los años ochenta se incorporan la Universidad del País Vasco (1981) y la Universidad de Sevilla (1989). El avance económico español tras la transición política o la expansión de los mercados de consumo y del sistema mediático provocaron que creciera rápidamente el número de centros que implantaban la titulación en Publicidad y Relaciones Públicas:

- CEU-San Pablo de Valencia (en 1990, dependiente de la Complutense);

- Colegio Europeo de Estudios Superiores (1991, actualmente Universidad Europea de Madrid);

- Colegio Universitario de Segovia (1991, actualmente Universidad de Valladolid);

- Universidad de Málaga (1992);

- Universitat Ramon Llull (1994); 
- Universidad de Vigo (1994);

- Universidad Antonio de Nebrija (1995);

- Universidad Pontificia de Salamanca (1996);

- Universidad de Alicante (1998);

- Universitat Jaume I (1999).
Más del $40 \%$ de las universidades espa-

ñolas oferta grados sobre Publicidad y Relaciones Públicas

Durante esta etapa se constata, en primer lugar, el crecimiento continuado en el número de alumnos, no solo en los estudios publicitarios sino en el conjunto de las titulaciones de Comunicación, con los primeros problemas de masificación en las aulas. En el curso 1989-1990 ya estaban matriculados en los estudios de Ciencias de la Información 21.818 estudiantes, frente a los 7.043 del curso 1980-1981 (Méndiz-Noguero, 2000, p. 204). En el curso 1999-2000 había en España 26.500 estudiantes de Comunicación y 4.264 licenciados y apenas tres años después, curso 2002-2003, 33.000 estudiantes y 5.374 licenciados, pasando a ser en el curso 2008-2009 unos 50.000 los estudiantes matriculados (Vivar-Zurita et al., 2010, p. 3).

En segundo lugar, en la década de los noventa se puso en marcha la renovación de los planes de estudio de estas titulaciones, que ya se venía avanzando desde la década anterior. Mediante el Real decreto 1497/1987 (España, 1987), de 27 de noviembre, por el que se establecen directrices generales comunes de los planes de estudio en los títulos universitarios de carácter oficial y validez en todo el territorio nacional, las nuevas titulaciones de Publicidad y Relaciones Públicas traen las siguientes novedades:

- se basan en asignaturas troncales, obligatorias y optativas organizadas en cuatrimestres frente a las tradicionales materias anuales;

- se reduce el número de años de la licenciatura, que pasa de cinco a cuatro;

- se incorporan contenidos renovados y más opciones para la libre elección del estudiante.

En tercer lugar, cabe subrayar el papel que en este período empezaron a adquirir las universidades privadas en la formación sobre Publicidad y Relaciones Públicas ya que, desde instancias gubernamentales y en cumplimiento con la normativa vigente, se comenzó a autorizar la apertura de centros privados o el reconocimiento como universidad de algunos que ya operaban con otra dimensión.

Con el inicio del siglo XXI se produjo un enorme incremento en el número de centros, también los de titularidad privada, motivado entre otras cuestiones por la expansión de los sistemas mediáticos y del panorama comunicativo y empresarial en general, así como por la aceptación social de estas profesiones y sus nuevas salidas laborales al albur de la revolución digital:

"empujados por circunstancias diversas en cada momento, pero siempre en una misma dirección expansiva, los estudios de Comunicación se han ido asentando entre las opciones de formación universitaria de mayor demanda y potencial de empleo en España en los últimos 30 años" (Martínez-Nicolás, 2020, p. 387).

Como consecuencia, despunta también la investigación sobre Publicidad, principalmente en dos momentos históricos: los primeros años de la década de los noventa y los primeros años del siglo XXI, sobre todo a partir de 2005 (Baladrón-Pazos; Manchado-Pérez; Correyero-Ruiz, 2017). Se trata de una evolución al alza que se produce también en la investigación sobre Relaciones Públicas, si bien en este caso -mención aparte de la indefinición de la disciplina (Magallón, 2004)- algunos estudios concluyen que la presencia de trabajos publicados de esta área es minoritaria en las revistas científicas españolas, representando menos del 5\% del total de lo publicado (Míguez-González; Baamonde-Silva; Corbacho-Valencia, 2014) y observándose una estabilización en la investigación publicada en los últimos años (Míguez-González; Costa-Sánchez, 2019). De igual modo, cuando la fuente analizada no son las revistas científicas sino las tesis doctorales defendidas, se constata que, pese a la evolución cuantitativa, la contribución al asentamiento teórico de la disciplina es limitada (Xifra; Castillo-Esparcia, 2006).

En el curso 2020-2021, existen en España 85 universidades (Ministerio de Universidades, 2021), de las cuales 50 son públicas y 35 privadas, si incluimos la Universidad ESIC en Madrid, hasta hace unos meses centro adscrito a la Universidad Rey Juan Carlos. En algo más del $40 \%$ de esas instituciones se imparten grados específicos sobre Publicidad y Relaciones Públicas (en dos de ellas de manera no presencial), a las que habría que sumar los centros adscritos. Los datos parecen corroborar el asentamiento de los estudios universitarios sobre Publicidad y Relaciones Públicas; dicha formación

"está plenamente consolidada y reforzada por una masa crítica de investigadores competitiva a nivel internacional" (Baladrón-Pazos, 2018, p. 63).

Ahora bien, no son menos ciertos los problemas en las plantillas de los docentes de Comunicación y también de Publicidad y Relaciones Públicas. Por una parte, con frecuencia padecen altos índices de temporalidad (Sierra-Sánchez, 2014) y la estabilidad laboral, por ejemplo mediante el acceso al funcionariado, ha estado muy influida por las condiciones políticas y económicas del país:

“el mayor desajuste observado tiene que ver con la evolución de la adjudicación de plazas a lo largo del tiempo, siendo dos períodos los que concentran un mayor número de plazas: el periodo previo a la habilitación donde apenas existían controles y requisitos evaluativos (2000-2003) y el de 2017-2019 cuando se permitió la contratación de nuevo, es decir tras la crisis financiera" (Repiso et al., 2020, p. 8). 
Por otra parte, los investigadores de Comunicación en el extranjero señalan también problemas comunes a la universidad española, como la endogamia y el clientelismo o bien otros específicos del área como su

"incardinación (...) en las humanidades, lo que distancia a la academia española del centro de gravedad cuantitativo que domina las Ciencias Sociales" (Seoane-Pérez; Martínez-Nicolás; Vicente-Mariño, 2020, p. 10).

\subsection{Bolonia y los nuevos grados sobre Publicidad y Relaciones Públicas}

El proceso de convergencia europeo fue otro reto clave y paso fundamental para la modernización de los estudios de Comunicación (Murciano-Martínez, 2010). El cambio que más ha renovado las titulaciones de Publicidad y Relaciones Públicas supuso una nueva adaptación de los planes de estudio diciendo adiós a las antiguas licenciaturas y dando la bienvenida a los grados universitarios. El ya referido Real decreto 1497/1987 (España, 1987) sentaba los cimientos para unos itinerarios formativos que se acomodasen al sistema imperante en Europa, dado que el objetivo del Plan Bolonia era precisamente hacer converger la oferta universitaria de los países de la UE. Fue el 25 de mayo de 1998 cuando los ministros responsables de la educación superior de Reino Unido, Alemania, Francia e Italia firmaron en París la Declaración de la Sorbona instando a la constitución y desarrollo del Espacio Europeo de Educación Superior:

"Es deber nuestro el consolidar y desarrollar las dimensiones intelectuales, culturales, sociales y técnicas de nuestro continente. Éstas han sido modeladas, en gran medida, por las universidades" (Declaración de la Sorbona, 1998).

Un año más tarde, el 19 de junio de 1999, ya fueron los ministros de los 29 países europeos los firmantes de la Declaración de Bolonia; el objetivo, desarrollar una política universitaria europea coordinada para conseguir una mayor competitividad en el panorama internacional:

"necesitamos asegurarnos de que el sistema de educación superior europeo adquiera un grado de atracción mundial igual al de nuestras extraordinarias tradiciones culturales y científicas" (Declaración de Bolonia, 1999).

Se buscaba

"una mejor eficiencia de los sistemas de educación superior (rendimiento académico, duración, equidad en el acceso y en el éxito en los estudios iniciales y a lo largo de la vida), una mayor diversidad en la oferta formativa (para responder a la diversidad de los estudiantes en cuanto a sus expectativas y sus maneras de aprender) y unos mecanismos de aseguramiento y mejora de la calidad del proceso de enseñanza/aprendizaje" (Haug, 2015, p. 12).

En España, el Real decreto 1393/2007, de 29 de octubre, por el que se establece la ordenación de las enseñanzas universitarias oficiales (España, 2007), consolidó la convergencia con Europa, en continuidad con lo establecido en la Ley Orgánica 6/2001, de 21 de diciembre, de Universidades (España, 2001). Como consecuencia de este proceso, las titulaciones de Publicidad y Relaciones Públicas, al igual que el resto de las de Comunicación, pasan a estructurarse en cuatro cursos académicos ( 240 créditos) conforme al sistema de créditos ECTS con el fin de que los nuevos grados universitarios fueran comparables entre todos los países europeos y se facilitase la movilidad de estudiantes, docentes y egresados. Por otra parte, el mencionado Real decreto 1393/2007 (España, 2007) permite la diversificación de la oferta formativa de las universidades, promoviendo que creen grados específicos frente al anterior sistema rígido del catálogo de títulos y arbitrando sistemas de garantía de calidad. Pero sin duda una de las implicaciones más ambiciosas de Bolonia fue el cambio en las metodologías de enseñanza-aprendizaje; pasar el foco de la enseñanza al aprendizaje dando mayor protagonismo al alumno en su proceso de aprendizaje, establecer que los objetivos formativos han de estar enfocados a la adquisición de competencias o promover la innovación en las metodologías docentes y los sistemas de evaluación son algunas de las novedades a las que tanto docentes como estudiantes han tenido que ir amoldándose. En este contexto se sitúan las guías docentes, elemento cardinal de la investigación que aquí presentamos, y su papel en la planificación de las enseñanzas. Las condiciones de la docencia universitaria (infraestructuras, tamaño de los grupos, etc.) han dificultado que esta filosofía se llevase plenamente a la práctica. Y también ha estado condicionada tanto por la necesaria actualización del profesorado como por la falta de hábito del alumnado respecto a las nuevas metodologías docentes. Según López-Berna

"la adaptación de las materias a los Grados en Publicidad y Relaciones Públicas en el Espacio Europeo de Educación Superior no ha sido en ningún caso basada en la evidencia científica” (López-Berna, 2014, p. 151),

y la oferta educativa ha estado demasiado condicionada por lo establecido en el Libro Blanco de los títulos de Grado en Comunicación (Aneca, 2005). López-Berna, Papí-Gálvez y Martín-Llaguno concluyen que esa adaptación al EEES

"se ha desarrollado de manera muy dispar, en otras palabras, hemos asistido a una 'convergencia divergente'" (López-Berna; Papí-Gálvez; Martín-Llaguno, 2016, p. 65).

\section{Objetivos, estado de la cuestión y método}

Precisamente para conocer la situación actual de la formación universitaria presencial de grado sobre Publicidad y Relaciones Públicas, después de estos cincuenta años desde el nacimiento de las Facultades de Ciencias de la Información y los sucesivos cambios que le han ido afectando, se ha realizado esta investigación. 
Respecto al estado de la cuestión en el estudio de dicha formación, cabe señalar, en primer lugar, que hasta el momento se han hecho diferentes trabajos sobre el conjunto de la formación en Publicidad y Relaciones Públicas en la universidad española, pero con planteamientos distintos al que aquí se propone. Muchos de ellos son ensayísticos o de revisión bibliográfica, algunos de los cuales se han referenciado en este artículo; otros son trabajos descriptivos que analizan los planes de estudio sin profundizar en cómo se desarrollan o ejecutan esos planes. Sobresalen los que han publicado Matilla y Hernández-Martínez con el fin de identificar la docencia en Relaciones Públicas (cabría destacar, entre otros: Matilla; Hernández-Martínez, 2012; Matilla; Hernández-Martínez; Losada-Díaz, 2010; Matilla; Hernández-Martínez; Compte-Pujol, 2018). A ellos es necesario añadir la valoración que en su tesis doctoral hace López-Berna (2014) de la adaptación de los estudios publicitarios al proceso de convergencia europea, dada su exhaustividad. La novedad de la investigación aquí presentada radica en basarse en el análisis no de los planes de estudio sino de las guías docentes, cuestión que también fundamenta otros estudios previos, aunque de alcance más restringido (Fanjul-Peyró; Pérez-Serrano; Cabezuelo-Lorenzo, 2010; Fondevila-Gascón et al., 2015; Gómez-Nieto; Tapia-Frade, 2017). El análisis de las guías docentes permite conocer de manera más completa no solo la superficie de los planes de estudio sino aspectos más profundos de la docencia de esta área, vinculados a otras cuestiones como actividades formativas y sistemas de evaluación. Con el análisis en esta investigación de las actividades formativas y los sistemas de evaluación se esperaba obtener un conocimiento que fuera más allá de los contenidos abordados en la docencia -cuestión presente en estudios previos- y ahondase en los modos en que dicha docencia se lleva a cabo de acuerdo con lo consignado en las guías docentes, en particular tras haber pasado varios años desde la renovación metodológica que planteaba el Plan Bolonia. En ese sentido, hubiera sido de interés el análisis de las competencias o el de los resultados de aprendizaje -que también se recogen en las guías docentes- si bien dichas cuestiones no fueron analizadas en la investigación realizada por la necesidad de acotar los objetivos y también por la complejidad de categorización de las mismas; se consideró que para abordarlo con rigor sería necesario un planteamiento metodológico ad hoc y diferente al empleado para los aspectos estudiados.

En segundo lugar, cabe referir también la existencia de trabajos previos pero de naturaleza más restringida, con frecuencia centrados en materias o asignaturas concretas que se imparten en los grados en Publicidad y Relaciones Públicas en España, por tanto con un alcance más limitado que el de nuestra investigación. Antes de referenciarlos, conviene subrayar que se excluyen aquellos trabajos únicamente centrados en alguna asignatura de algún centro universitario específico aún cuando se basen en el estudio de guías docentes; así, se mencionan solo los que analizan la o las materias en una diversidad de centros formativos y, por ende, se puede considerar que implican un acercamiento más amplio al estudio de la formación sobre Publicidad y Relaciones Públicas en España pese a que sea focalizado en materias concretas. Seleccionando únicamente los que implican ese acercamiento más amplio, es necesario, por una parte, referir tanto los que lo abordan con un planteamiento metodológico que va más allá de la revisión bibliográfica (Alegre-Rodríguez, 2012; Alonso-González, 2008; Castelló-Martínez, 2012; 2020; Gómez-Nieto; Tapia-Frade, 2017; Perlado-Lamo-de-Espinosa; Saavedra-Llamas; Rubio-Romero, 2016; Torres-Romay, 2010), como los que lo hacen basándose en la revisión bibliográfica (Alemany-Martínez, 2020; Alonso-González, 2004; Castelló-Martínez; Tur-Viñes, 2019; Corbacho-Valencia, 2013; Estanyol-i-Casals, 2012; Flores-Mayorga; Roca-Correa, 2011; Orbea-Mira; Tur-Viñes; Fernández-Poyatos, 2006a; 2006b; Ramos-Serrano; Muñiz-Velázquez, 2018; Tur-Viñes, 2006; Vázquez-Gestal, 2001). Por otra parte, a esos estudios de dimensión más nacional, aunque centrados en materias específicas, cabe añadir las investigaciones focalizadas en zonas geográficas particulares y que no abarcan el total de la oferta universitaria del área en España, como sí lo hacemos en nuestra investigación: también en este caso los hay de naturaleza más ensayística (Pena-Rodríguez; Rúas-Araújo, 2003) o bien con metodologías más completas, como los sectoriales de Matilla y Hernández (de los cuales cabría destacar Matilla; Hernández-Martínez; Compte-Pujol, 2016) o el de Fondevila-Gascón et al. (2015). Se excluyen los trabajos vinculados a universidades concretas que, como dijimos, creemos no es de interés referenciar, excepto, por su carácter recopilatorio, el volumen coordinado por Ramírez-Alvarado y Clemente-Mediavilla (2020) y los muy numerosos referidos a actividades de innovación metodológica en asignaturas específicas de centros igualmente específicos.

Junto a todos esos estudios, la investigación aquí presentada propone un planteamiento holístico y además lo hace abordando diversas perspectivas que a continuación se recogen en los objetivos de la investigación, para concluir un balance de mayor profundidad sobre el conjunto de la formación del área. Conviene subrayar, una vez más, que en nuestra investigación se analiza la oferta de grado, excluyendo la de posgrado, que también ha sido estudiada con anterioridad (Cuenca-Fontbona et al., 2017; Hernández-Martínez; Losada-Díaz; Matilla, 2009) y que desde luego es fundamental en la promoción de la investigación en Comunicación (Baños-González; Martínez-Gallego; Papí-Gálvez, 2021).

La investigación llevada a cabo constituyó un estudio descriptivo sobre la formación en los grados universitarios presenciales sobre Publicidad y Relaciones Públicas que se imparten en España, a través del análisis de sus guías docentes -instrumento clave en el marco del EEES y el sistema de créditos ECTS- con el objetivo de conocer cómo se está llevando a cabo dicha formación tanto en cuanto al qué se enseña como al cómo se enseña. Se basó en el análisis de las guías docentes dado que éstas, en coherencia con lo recogido en las memorias verificadas de los grados y de acuerdo a los sistemas de garantía de calidad establecidos, son los documentos que reflejan de manera más certera y precisa cómo es esa formación; aparte de su grado de aplicación en la práctica docente que, en todo caso, se ha de presumir sin olvidar que la dinámica de la clase es la que plasma los principios recogidos en las guías docentes (Fanjul-Peyró; Pérez-Serrano; 
Cabezuelo-Lorenzo, 2010). Hay que tener en cuenta que la guía docente es un instrumento que va mucho más allá de los contenidos o temario, elemento central de los antiguos programas de asignaturas, estableciendo también cuestiones más vinculadas al proceso de enseñanza-aprendizaje del estudiante, algunas de las cuales se recogen como objetivos de nuestro trabajo. De hecho, el objetivo genérico de nuestra investigación se tradujo en los siguientes objetivos específicos:

1. Identificar los grados, y caracterizar los centros de formación y asignaturas activas de la formación presencial universitaria de grado sobre Publicidad y Relaciones Públicas en España;

2. Identificar y cuantificar los campos temáticos presentes en la formación universitaria presencial de grado sobre Publicidad y Relaciones Públicas en España;

3. Identificar y cuantificar las actividades formativas contempladas en el marco de las metodologías docentes utilizadas en la formación universitaria presencial de grado sobre Publicidad y Relaciones Públicas en España;

4. Identificar y cuantificar los sistemas de evaluación empleados en la formación universitaria presencial de grado sobre Publicidad y Relaciones Públicas en España.

En una primera fase, se identificaron -mediante acceso a los datos del Ministerio de Universidades y consulta de la oferta formativa de las universidades españolas en sus webs corporativas- los grados universitarios que se imparten en España de manera presencial en el curso 2020-2021, de acuerdo con los siguientes criterios:

- se seleccionaron los grados sobre Publicidad y Relaciones Públicas, bien conjuntamente de los dos campos o bien centrados en uno solo de ellos; no se consideraron aquellos que vinculan la formación en Relaciones Públicas a ámbitos distintos a los analizados en esta investigación, como es el caso del Periodismo, o con campos muy específicos, como es el Protocolo;

- se seleccionaron los grados simples, siendo excluidos los dobles grados dado que sus asignaturas corresponden a titulaciones oficiales simples y por tanto se generaría una redundancia de datos, así como aquellos en los que un porcentaje de la formación se imparte en universidades extranjeras, porque se pretendía analizar la docencia universitaria en España. La colección de grados y sus correspondientes centros de formación se recoge en la tabla 1 y asciende a 41 titulaciones oficiales.

En una segunda fase, para el logro de los objetivos de la investigación se analizaron las guías docentes de todas las asignaturas activas de los planes de estudio de los grados seleccionados. En el caso de la convivencia en un mismo centro de formación de planes en extinción y planes nuevos se seleccionaron de cada uno de ellos las asignaturas activas en el curso 2020-2021. Esto fue así ya que el objetivo de nuestra investigación era describir la situación actual, para lo cual solo se debían considerar las asignaturas activas, además de que para las inactivas es lógico que no existiese guía docente. Si de un mismo centro fueron analizados planes nuevos y planes en extinción con distinta denominación, en la tabla 1 se recogen ambos. Además, se excluyeron las guías docentes de asignaturas especiales (las referidas a trabajo fin de grado, prácticas en empresas o reconocimiento de créditos) dado que por su especificidad no cuentan con una formación comparable al resto de las que integran los itinerarios formativos. Las guías fueron descargadas de las webs corporativas de los centros de formación y en caso de ausencia de alguna se contactó con la persona responsable de la titulación para intentar solventar la situación. Finalmente se analizaron 1.815 guías docentes correspondientes a 10.224 créditos ECTS de formación universitaria presencial de grado sobre Publicidad y Relaciones Públicas impartida en 38 centros de formación en España. Se diseñó una ficha de codificación compuesta por 13 variables y sus respectivas categorías (tabla 2) acordes a los distintos objetivos de la investigación, que se aplicó a cada guía docente. Uno de ellos, relativo al campo temático abordado en la asignatura, era de respuesta múltiple, ya que en algunos casos se podía dar más de un campo. Por otra parte, en los referidos a las actividades formativas y a los sistemas de evaluación, se evaluaban varias alternativas, aunque con respuesta única dentro de cada categoría. De acuerdo con un libro de códigos previamente diseñado, se llevó a cabo la codificación mediante el sistema de double-check y resolviendo las posibles contradicciones en reuniones de los investigadores codificadores, garantizando así la fiabilidad de dicha codificación. Para el tratamiento de los datos se utilizó el programa IBM SPSS Statistics versión 27, a partir de una base de datos formada por 57 variables finales, derivadas de las originales de las fichas de codificación. Para la variable de ámbitos temáticos se creó un conjunto de respuesta múltiple, con el fin de describir adecuadamente la información recogida. 
Tabla 1. Relación de grados y centros de formación

\begin{tabular}{|c|c|}
\hline Titulación oficial presencial & Centro de formación \\
\hline Grado en Publicidad y Relaciones Públicas & Centro de Enseñanza Superior Alberta Giménez CESAG - Universidad Pontificia de Comillas \\
\hline Grado en Publicidad y Relaciones Públicas & Centro de Estudios Superiores Universitarios de Galicia CESUGA - Universidad San Jorge \\
\hline Grado en Publicidad y Relaciones Públicas & Centro Universitario EUSA - Universidad de Sevilla \\
\hline $\begin{array}{l}\text { Grado en Publicidad, Relaciones Públicas y Marketing } \\
\text { Grado en Publicidad y Relaciones Públicas }\end{array}$ & Escola Superior de Relacions Públiques - Universitat de Barcelona \\
\hline Grado en Comunicación y Relaciones Públicas & Escuela Superior de Gestión Empresarial y Marketing ESIC - Universidad Miguel Hernández \\
\hline Grado en Publicidad y Relaciones Públicas & $\begin{array}{l}\text { Escuela Superior de Gestión Empresarial y Marketing ESIC (Universidad ESIC) - Universi- } \\
\text { dad Rey Juan Carlos }\end{array}$ \\
\hline Grado en Publicidad, Marketing y Relaciones Públicas & $\begin{array}{l}\text { ESERP The Barcelona School of Business and Social Science - Universitat de Vic / Central } \\
\text { de Catalunya }\end{array}$ \\
\hline Grado en Publicidad y Relaciones Públicas & Universidad Antonio de Nebrija \\
\hline Grado en Publicidad y Relaciones Públicas & Universidad Cardenal Herrera CEU \\
\hline Grado en Publicidad y Relaciones Públicas & Universidad Católica San Antonio \\
\hline Grado en Publicidad y Relaciones Públicas & Universidad Complutense de Madrid \\
\hline Grado en Publicidad y Relaciones Públicas & Universidad de Alicante \\
\hline Grado en Publicidad y Relaciones Públicas & Universidad de Cádiz \\
\hline Grado en Publicidad y Relaciones Públicas & Universidad de Málaga \\
\hline Grado en Publicidad y Relaciones Públicas & Universidad de Murcia \\
\hline Grado en Publicidad y Relaciones Públicas & Universidad de Sevilla \\
\hline Grado en Publicidad y Relaciones Públicas & Universidad de Valladolid \\
\hline Grado en Publicidad y Relaciones Públicas & Universidad de Vigo \\
\hline Grado en Publicidad y Relaciones Públicas & Universidad del País Vasco \\
\hline Grado en Comunicación Publicitaria & Universidad Europea de Canarias \\
\hline $\begin{array}{l}\text { Grado en Publicidad } \\
\text { Grado en Publicidad y Relaciones Públicas }\end{array}$ & Universidad Europea de Madrid \\
\hline Grado en Publicidad y Relaciones Públicas & Universidad Europea del Atlántico \\
\hline Grado en Publicidad y Relaciones Públicas & Universidad Europea Miguel de Cervantes \\
\hline Grado en Publicidad & Universidad Francisco de Vitoria \\
\hline Grado en Publicidad y Relaciones Públicas & Universidad Pontificia de Salamanca \\
\hline Grado en Publicidad y Relaciones Públicas & Universidad Rey Juan Carlos \\
\hline Grado en Publicidad y Relaciones Públicas & Universidad San Jorge \\
\hline Grado en Publicidad y Relaciones Públicas & Universidad San Pablo CEU \\
\hline Grado en Publicidad y Relaciones Públicas & Universidad Villanueva \\
\hline Grado en Publicidad y Relaciones Públicas & Universitat Abat Oliba CEU \\
\hline $\begin{array}{l}\text { Grado en Publicidad y Relaciones Públicas. } \\
\text { Grado en Comunicación de las organizaciones }\end{array}$ & Universitat Autònoma de Barcelona \\
\hline Grado en Publicidad y Relaciones Públicas & Universitat de Girona \\
\hline Grado en Publicidad y Relaciones Públicas & Universitat de Vic / Universitat Central de Catalunya \\
\hline Grado en Publicidad y Relaciones Públicas & Universitat Internacional de Catalunya \\
\hline Grado en Publicidad y Relaciones Públicas & Universitat Jaume I de Castelló \\
\hline Grado en Publicidad y Relaciones Públicas & Universitat Pompeu Fabra \\
\hline Grado en Publicidad, Relaciones Públicas y Marketing & Universitat Ramon Llull \\
\hline Grado en Publicidad y Relaciones Públicas & Universitat Rovira i Virgili \\
\hline
\end{tabular}


Tabla 2. Variables y categorías

\begin{tabular}{|c|c|}
\hline Denominación de centro de formación & $\begin{array}{l}\text { Universitat Pompeu Fabra / Universitat Autònoma de Barcelona / Universidad de Sevilla / Universidad } \\
\text { Rey Juan Carlos / Universidad de Vigo / Universidad de Málaga / Universidad de Murcia / Universitat } \\
\text { Jaume I de Castelló / Universidad Complutense de Madrid / Universidad del País Vasco / Universitat } \\
\text { Rovira i Virgili / Universidad Villanueva / Universitat de Vic - Universitat Central de Catalunya / Uni- } \\
\text { versidad Antonio de Nebrija / Universidad San Pablo CEU / Universidad Cardenal Herrera CEU / Univer- } \\
\text { sitat Abat Oliba CEU / Universidad Católica San Antonio / Universitat de Girona / Universidad Europea } \\
\text { de Madrid / Universidad Europea de Canarias / Universidad Francisco de Vitoria / Universidad Europea } \\
\text { del Atlántico / Universidad Europea Miguel de Cervantes / Universidad Pontificia de Salamanca / Uni- } \\
\text { versitat Ramon Llull / Universidad San Jorge / Universidad Internacional de Cataluña / Universidad de } \\
\text { Valladolid / Universidad de Cádiz / Universidad de Alicante / Escuela Superior de Gestión Empresarial y } \\
\text { Marketing ESIC - Universidad Miguel Hernández / Escuela Superior de Gestión Empresarial y Marketing } \\
\text { ESIC (Universidad ESIC) - Universidad Rey Juan Carlos / ESERP The Barcelona School of Business and } \\
\text { Social Science - Universitat de Vic - Central de Catalunya / Escola Superior de Relacions Públiques - } \\
\text { Universitat de Barcelona / Centro Universitario EUSA - Universidad de Sevilla / Centro de Enseñanza } \\
\text { Superior Alberta Giménez CESAG - Universidad Pontificia de Comillas / Centro de Estudios Superiores } \\
\text { Universitarios de Galicia CESUGA - Universidad San Jorge }\end{array}$ \\
\hline Tipo de centro de formación & Público / Privado / Adscrito a público / Adscrito a privado \\
\hline Denominación de grado & $\begin{array}{l}\text { Publicidad y Relaciones Públicas / Publicidad / Comunicación publicitaria / Publicidad, Relaciones } \\
\text { Públicas y Marketing / Publicidad, marketing y Relaciones Públicas / Comunicación y Relaciones } \\
\text { Públicas / Comunicación de las organizaciones }\end{array}$ \\
\hline Denominación de asignatura & (no categórico) \\
\hline Tipo de asignatura & Formación básica / Obligatoria / Optativa \\
\hline Asignatura tipo taller & Sí / No \\
\hline Número de créditos de asignatura & $12 / 11 / 10 / 9 / 8 / 7 / 6 / 5 / 4 / 3 / 2 / 1$ \\
\hline Idioma de impartición de asignatura & Castellano u otra lengua española / Inglés / Ambos \\
\hline Curso de impartición de asignatura & Primero / Segundo / Tercero / Cuarto / Quinto / Se puede cursar en varios cursos \\
\hline Semestre de impartición de asignatura & Primero / Segundo / Anual / Se puede cursar en varios cursos semestres \\
\hline Campos temáticos de asignatura & $\begin{array}{l}\text { TNC Antropología / TNC Ciencia Política / TNC Derecho / TNC Economía / TNC Educación / TNC } \\
\text { Empresa / TNC Estadística / TNC Ética / TNC Geografía / TNC Historia / TNC Humanidades / TNC } \\
\text { Psicología / TNC Sociología / TNC Lengua / TNC Idioma / TNC Nuevas Tecnologías / TNC Teología / } \\
\text { TC Genérica comunicación / TC Periodismo comunicación / TC Audiovisual comunicación / Intro- } \\
\text { ducción a la publicidad / Teoría de la publicidad / Historia de la publicidad / Derecho publicitario / } \\
\text { Ética y deontología de la publicidad / Documentación publicitaria y gestión de datos / Psicología } \\
\text { de la publicidad / Estructura de la publicidad / Dirección y gestión de cuentas / Planificación } \\
\text { estratégica publicitaria / Creatividad y procesos de creación / Dirección de arte / Redacción publi- } \\
\text { citaria / Lenguaje y discurso publicitario / Planificación y medios publicitarios / Branding y gestión } \\
\text { de marca / Investigación en publicidad / Diseño y producción impresa publicitaria / Fotografía } \\
\text { publicitaria / Producción y realización audiovisual publicitaria / Publicidad y marketing digital / } \\
\text { Publicidad especializada / Publicidad y procesos culturales / Introducción a las Relaciones Públicas } \\
\text { / Teoría de las RR.PP. / Historia de las Relaciones Públicas / Derecho y Relaciones Públicas / Ética } \\
\text { y deontología de las Relaciones Públicas / Documentación en Relaciones Públicas y gestión de } \\
\text { datos / Psicología de las Relaciones Públicas / Estructura de las Relaciones Públicas / Redacción en } \\
\text { Relaciones Públicas / Planificación estratégica de las Relaciones Públicas / Técnicas de Relaciones } \\
\text { Públicas / Gestión de intangibles en Relaciones Públicas / Investigación en Relaciones Públicas / } \\
\text { Dirección de comunicación y gabinetes / Relaciones Públicas digitales / Relaciones Públicas es- } \\
\text { pecializadas / Fotografía en Relaciones Públicas / Producción en Relaciones Públicas / Relaciones } \\
\text { Públicas y procesos culturales }\end{array}$ \\
\hline $\begin{array}{l}\text { Actividades formativas de asignatura } \\
\text { (en número de horas) }\end{array}$ & $\begin{array}{l}\text { Clases teóricas / Clases prácticas / Lecturas y/o visionados / Trabajos y/o resolución de casos / } \\
\text { Seminarios y/o talleres / Debates y/o participación / Tutorías / Exposiciones orales y/o presenta- } \\
\text { ciones públicas / Actividades complementarias / Pruebas de evaluación / Otras }\end{array}$ \\
\hline $\begin{array}{l}\text { Sistemas de evaluación de asignatura } \\
\text { (en porcentaje sobre 100) }\end{array}$ & $\begin{array}{l}\text { Prueba escrita / Prueba oral / Trabajo y/o proyecto / Prácticas y/o análisis de casos / Exposiciones } \\
\text { orales y/o presentaciones públicas / Participación / Actividades complementarias }\end{array}$ \\
\hline
\end{tabular}

TC: Transversal de Comunicación; TNC: Transversal No de Comunicación

\section{Resultados}

En primer lugar, la identificación de los grados y la caracterización de los centros de formación y asignaturas de la formación presencial universitaria sobre Publicidad y Relaciones Públicas en España fue uno de los objetivos específicos de nuestra investigación. Como se indicó anteriormente, se identificaron 41 titulaciones oficiales, siendo aproximadamente el $80 \%$ grados con la denominación tradicional de Publicidad y Relaciones Públicas, como se puede observar en la tabla 1. En torno al $60 \%$ de esas titulaciones son impartidas en centros de formación de gestión privada (tanto universidades como centros adscritos) y el resto en instituciones públicas. En consecuencia, este mismo predominio de lo privado se observa en cuanto a las 1.815 asignaturas correspondientes a esas titulaciones seleccionadas para el análisis de sus guías docentes. Así, respecto a la caracterización de las asignaturas activas de la formación presencial universitaria de grado sobre Publicidad y Relaciones Públicas, la mayoría -en concreto el 59,1\%- se imparte en centros de formación privados. 
Como se aprecia en la tabla 3, el porcentaje de docencia ofertado en universidades públicas y privadas es prácticamente idéntico, pero al sumar la docencia que se lleva a cabo desde centros adscritos -también privados- se evidencia el peso que actualmente ha llegado a alcanzar la iniciativa privada.

Respecto al tipo de asignatura (tabla 4), la distribución es acorde a lo establecido por las leyes, con lo que la mayoría son asignaturas obligatorias. El Real decreto 1393/2007 (España, 2007), de 29 de octubre, por el que se establece la ordenación de las enseñanzas universitarias oficiales, estableció un porcentaje mínimo de asignaturas de formación básica del $25 \%$. Sin embargo, en nuestra investigación este porcentaje es inferior en pro, principalmente, de un mayor peso de las asignaturas optativas. Esto es debido a que nuestra intención siempre ha sido la de conocer el total de la formación presencial sobre Publicidad y Relaciones Públicas, por lo que se han tomado como base del análisis todas las asignaturas activas integradas en los itinerarios formativos de los grados seleccionados y son precisamente las optativas aquellas sobre las cuales el estudiante tiene una mayor posibilidad de elección sin necesidad de cursarlas todas.

Algo similar sucede en cuanto a la distribución de las asignaturas por cada uno de los cuatro cursos y cada semestre de los grados. Es muy parecida entre todos, habiendo en el caso de los cursos solo un $4,5 \%$ de asignaturas que pueden ser realizadas en varios de ellos (también en este caso la mayoría son asignaturas optativas en las que el estudiante puede elegir el curso en el que se matricula de las mismas). En cuanto a los semestres, también es mínimo el porcentaje de asignaturas que permiten ser cursadas en semestres diferentes $(3,1 \%)$ o bien que tienen una duración anual (2\%).

Por otra parte, como se aprecia en la tabla 5, lo más frecuente es construir los planes de estudio con asignaturas de 6 créditos (suponen el 78,8\% del total), seguidas de las de 3 y 4 créditos. Conviene señalar que una mínima parte de asignaturas tiene una duración en créditos con decimales, en cuyo caso para no complicar la representación de los datos, en la tabla adjunta se han asimilado al número de créditos inmediatamente superior en números redondos. Se observa, en todo caso, una clara preferencia por asignaturas de corta duración, dado que las que tienen una duración superior a los 6 créditos son porcentualmente residuales. Asimismo, son las asignaturas de corta duración las que habitualmente tienen una denominación de taller o seminario, si bien son solo 66 (el 3,6\% del total) las que tienen este tipo de enfoque en su denominación.

Es importante el dato referente al idioma en que se imparte la formación presencial sobre Publicidad y Relaciones Públicas. El uso del inglés es minoritario, según lo consignado en las guías docentes del curso 2020-2021 sobre el idioma que se emplea en la docencia de la asignatura: el 90,8\% de la docencia se lleva a cabo en español o cualquier otra lengua cooficial en la Comunidad Autónoma correspondiente, solo el 7,1\% en inglés y el restante 2,1\% en modo bilingüe. Si diferenciamos entre centros públicos y privados, se observa que en los privados la impartición en inglés sube al 10,2\% y en los públicos baja al 2,6\%. Lo mismo sucede con la docencia bilingüe, con porcentajes del 2,3\% y 1,9\%, respectivamente. En la tabla 6 se recogen los datos desagregados por tipo de centro de formación, que evidencian el papel fundamental que cumplen los centros privados en la promoción de la docencia en inglés o bilingüe; no solo las universidades privadas, sino más aún los centros adscritos a universidades públicas y sobre todo los adscritos a universidades privadas, en donde la suma de la formación en inglés y bilingüe se acerca al 30\%. Respecto a la cuestión del idioma, también con-

Tabla 3. Tipo de centro de formación

\begin{tabular}{|l|c|c|}
\hline Tipo de centro & Frecuencia & Porcentaje \\
\hline Público & 743 & 40,9 \\
\hline Privado & 735 & 40,5 \\
\hline Adscrito a público & 207 & 11,4 \\
\hline Adscrito a privado & 130 & 7,2 \\
\hline Total & 1.815 & 100 \\
\hline
\end{tabular}

Tabla 4. Tipo de asignatura

\begin{tabular}{|l|c|c|}
\hline Tipo de asignatura & Frecuencia & Porcentaje \\
\hline Obligatoria & 920 & 50,7 \\
\hline Formación básica & 391 & 21,5 \\
\hline Optativa & 504 & 27,8 \\
\hline Total & 1.815 & 100 \\
\hline
\end{tabular}

Tabla 5. Número de créditos de la asignatura

\begin{tabular}{|c|c|c|}
\hline No de créditos & Frecuencia & Porcentaje \\
\hline 1 & 3 & 0,2 \\
\hline 2 & 22 & 1,2 \\
\hline 3 & 180 & 9,9 \\
\hline 4 & 97 & 5,3 \\
\hline 5 & 29 & 1,6 \\
\hline 6 & 1.431 & 78,8 \\
\hline 7 & 2 & 0,1 \\
\hline 8 & 9 & 0,5 \\
\hline 9 & 24 & 1,3 \\
\hline 12 & 18 & 1,0 \\
\hline Total & 1.815 & 100 \\
\hline
\end{tabular}

Tabla 6. Tipo de centro por idioma de impartición

\begin{tabular}{|l|l|c|c|c|c|}
\hline \multicolumn{2}{|c|}{ Tipo de centro } & \multicolumn{3}{c|}{ Idioma } & \multirow{2}{*}{ Total } \\
\cline { 3 - 6 } & Español & Inglés & Ambos & \\
\hline \multirow{2}{*}{$\begin{array}{l}\text { Universidad } \\
\text { pública }\end{array}$} & Recuento & 710 & 19 & 14 & 743 \\
\cline { 2 - 6 } & $\%$ & 95,6 & 2,6 & 1,9 & 100 \\
\hline \multirow{2}{*}{$\begin{array}{l}\text { Universidad } \\
\text { privada }\end{array}$} & Recuento & 658 & 55 & 22 & 735 \\
\cline { 2 - 6 } & $\%$ & 89,5 & 7,5 & 3,0 & 100 \\
\hline \multirow{2}{*}{$\begin{array}{l}\text { Adscrito a } \\
\text { público }\end{array}$} & Recuento & 188 & 19 & 0 & 207 \\
\cline { 2 - 6 } & $\%$ & 90,8 & 9,2 & 0,0 & 100 \\
\hline \multirow{2}{*}{$\begin{array}{l}\text { Adscrito a } \\
\text { privado }\end{array}$} & Recuento & 92 & 35 & 3 & 130 \\
\cline { 2 - 6 } & $\%$ & 70,8 & 26,9 & 2,3 & 100 \\
\hline \multirow{2}{*}{ Total } & Recuento & 1.648 & 128 & 39 & 1.815 \\
\cline { 2 - 6 } & $\%$ & 90,8 & 7,1 & 2,1 & 100 \\
\hline
\end{tabular}


viene destacar que la docencia en inglés más bilingüe es mayor en las asignaturas optativas (en conjunto alcanza el 10,5\%) y como consecuencia en las que pueden ser realizadas en cursos distintos (en conjunto supone el $33 \%)$, además de crecer a medida que es menor la duración por créditos de las asignaturas (por ejemplo, también en conjunto, llega al $18,3 \%$ en las asignaturas de 3 créditos).

En segundo lugar, otro de los objetivos específicos de nuestra investigación fue identificar y cuantificar los campos temáticos presentes en la formación universitaria presencial de grado sobre Publicidad y Relaciones Públicas en España. Para entender los resultados a continuación expuestos, queremos hacer constar algunas aclaraciones respecto a la recogida de datos. Aunque estén consignadas en el epígrafe metodológico de este artículo, por su carácter específico creemos que es conveniente y útil para el lector hacer que consten aquí. Para este objetivo se establecieron 42 categorías de campos temáticos referidos tanto a Publicidad como a Relaciones Públicas, tomando como referencia inicial las áreas de estudio convencionalmente consideradas en estas disciplinas; a ellas se añadieron otras 3 categorías que permitiesen caracterizar las asignaturas transversales de Ciencias de la Comunicación (sobre Comunicación en general, Periodismo o Comunicación Audiovisual) así como 17 categorías para caracterizar las asignaturas transversales que no fueran de Ciencias de la Comunicación, principalmente las de formación básica (incluyendo entre esas categorías todas las materias recogidas para la rama de Ciencias Sociales y Jurídicas en el Real decreto 1393/2007) (España, 2007). Se consultaron los temarios de las asignaturas recogidos en las guías docentes, dado que los títulos no siempre dan una visión certera de los contenidos de cada asignatura, y se asignó a cada asignatura una, o bien varias, de esas categorías, en función de lo recogido en dichos temarios. La posibilidad de respuesta múltiple explica que, en esta ocasión, el número de datos sea superior a las 1.815 guías docentes de asignaturas analizadas, al poderse tratar varios campos temáticos en una misma asignatura. Es algo frecuente, por ejemplo, en asignaturas que abordan en parte la disciplina publicitaria y en parte la de Relaciones Públicas. Además, dada la gran diversidad de asignaturas que integran los distintos planes de estudio, en caso de que alguna no se pudiese encuadrar en ninguna de las categorías temáticas preestablecidas se generó una nueva categoría; son, precisamente por la excepcionalidad de estos casos, categorías muy residuales sobre el total de las guías docentes, casos muy puntuales con porcentajes muy reducidos sobre el total.

Teniendo esto en cuenta, en la tabla 7 se recogen los principales campos temáticos abordados en la formación universitaria presencial sobre Publicidad y Relaciones Públicas en España, en concreto los presentes en al menos un $1 \%$ de las
Tabla 7. Principales temas

\begin{tabular}{|c|c|c|c|}
\hline \multirow{2}{*}{ Temas } & \multicolumn{2}{|c|}{ Respuestas } & \multirow{2}{*}{$\begin{array}{l}\% \text { de } \\
\text { casos }\end{array}$} \\
\hline & $\mathbf{N}$ & $\%$ & \\
\hline TC Genérica Comunicación & 195 & 9,0 & 10,7 \\
\hline TNC Empresa & 130 & 6,0 & 7,2 \\
\hline TC Audiovisual Comunicación & 101 & 4,6 & 5,6 \\
\hline Creatividad publicitaria y procesos de creación & 85 & 3,9 & 4,7 \\
\hline Publicidad y marketing digital & 79 & 3,6 & 4,4 \\
\hline TNC Sociología & 79 & 3,6 & 4,4 \\
\hline Diseño y producción impresa publicitaria & 72 & 3,3 & 4,0 \\
\hline TNC Humanidades & 63 & 2,9 & 3,5 \\
\hline Introducción a las Relaciones Públicas & 54 & 2,5 & 3,0 \\
\hline Producción y realización audiovisual publicitaria & 54 & 2,5 & 3,0 \\
\hline Planificación y medios publicitarios & 54 & 2,5 & 3,0 \\
\hline Planificación estratégica de las RR.PP. & 46 & 2,1 & 2,5 \\
\hline Introducción a la publicidad & 45 & 2,1 & 2,5 \\
\hline TNC Lengua & 42 & 1,9 & 2,3 \\
\hline TNC Nuevas tecnologías & 42 & 1,9 & 2,3 \\
\hline Gestión de intangibles en RR.PP. & 41 & 1,9 & 2,3 \\
\hline TNC Idioma & 39 & 1,8 & 2,1 \\
\hline Planificación estratégica publicitaria & 39 & 1,8 & 2,1 \\
\hline Estructura de la publicidad & 36 & 1,7 & 2,0 \\
\hline Historia de la publicidad & 34 & 1,6 & 1,9 \\
\hline Investigación en publicidad & 34 & 1,6 & 1,9 \\
\hline Derecho publicitario & 33 & 1,5 & 1,8 \\
\hline Branding y gestión de marca & 33 & 1,5 & 1,8 \\
\hline Protocolo y organización de eventos & 31 & 1,4 & 1,7 \\
\hline Técnicas de Relaciones Públicas & 30 & 1,4 & 1,7 \\
\hline Dirección de arte & 28 & 1,3 & 1,5 \\
\hline Redacción publicitaria & 28 & 1,3 & 1,5 \\
\hline Fotografía publicitaria & 28 & 1,3 & 1,5 \\
\hline TNC Historia & 27 & 1,2 & 1,5 \\
\hline Lenguaje y discurso publicitario & 27 & 1,2 & 1,5 \\
\hline TC Periodismo Comunicación & 27 & 1,2 & 1,5 \\
\hline TNC Economía & 26 & 1,2 & 1,4 \\
\hline Dirección y gestión de cuentas & 25 & 1,1 & 1,4 \\
\hline Publicidad y procesos culturales & 25 & 1,1 & 1,4 \\
\hline Comunicación política & 25 & 1,1 & 1,4 \\
\hline Ética y deontología de la publicidad & 24 & 1,1 & 1,3 \\
\hline RR.PP. especializadas & 23 & 1,1 & 1,3 \\
\hline TNC Derecho & 21 & 1,0 & 1,2 \\
\hline Psicología de la publicidad & 19 & 0,9 & 1,0 \\
\hline Ética y deontología de las Relaciones Públicas & 19 & 0,9 & 1,0 \\
\hline
\end{tabular}

TC: Transversal de Comunicación; TNC: Transversal No de Comunicación 
asignaturas. Sin ánimo de exponer todos los datos, pues se recogen con detalle en la tabla, es relevante destacar las principales tendencias que se observan. Por un lado, tal y como más adelante se comentará, el importante peso de los contenidos sobre Ciencias de la Comunicación, principalmente aquellos que son genéricos de Comunicación y en segundo lugar los ligados a la Comunicación Audiovisual; estos campos temáticos están presentes, respectivamente, en el 10,7\% y en el 5,6\% de las asignaturas, mientras que los contenidos de Comunicación vinculados a Periodismo tienen menos relevancia, como se observa en la tabla. Por otro lado, también es destacado el abordaje de los campos temáticos transversales que no son de Comunicación, principalmente los vinculados con la materia Empresa (que está presente en el 7,2\% de las asignaturas, siendo fundamentales en este caso las asignaturas de Marketing, incluidas en esta categoría), con Sociología $(4,4 \%)$ y con Humanidades (3,5\%, principalmente asignaturas de movimientos literarios o artísticos). Ya centrándonos en los ámbitos de Publicidad y Relaciones Públicas, los que tienen una mayor presencia en la formación de los grados de esta área son Creatividad publicitaria y procesos de creación (campos temático presente en el $4,7 \%$ de las asignaturas) y Publicidad y marketing digital (4,4\%); además, respecto al estudio de la creatividad en Publicidad hay que tener en cuenta que los campos Dirección de arte y Redacción publicitaria se integran en el ejercicio profesional de la creatividad publicitaria, de modo que reforzarían el peso que representa sobre el total de la docencia en Publicidad y Relaciones Públicas. Le siguen Diseño y producción impresa publicitaria (4\%), Introducciones a las Relaciones Públicas (3\%), Producción y realización audiovisual publicitaria (3\%), Planificación y medios publicitarios (3\%), Planificación estratégica de las Relaciones Públicas (2,5\%) e Introducciones a la Publicidad (2,5\%). No queremos extendernos demasiado en el comentario de los datos, que están detallados en la tabla para información del lector, pero en cualquier caso los campos temáticos sobre Publicidad o Relaciones Públicas que en los primeros veinticinco puestos siguen a los indicados son, por este orden, Gestión de intangibles en Relaciones Públicas, Planificación estratégica publicitaria, Estructura de la publicidad, Historia de la publicidad, Investigación en publicidad, Derecho publicitario, Branding y gestión de marca, Protocolo y organización de eventos y, por último, Técnicas de Relaciones Públicas.

Asimismo, para una mayor claridad en la exposición de resultados, se agrupó el conjunto de campos temáticos en cuatro categorías genéricas: Publicidad, Relaciones Públicas, Transversal de Comunicación y Transversal No de Comunicación (tabla 8). En casi la mitad de las asignaturas se abordan campos que no son especializados ni en Publicidad ni en Relaciones Públicas: más campos temáticos transversales no vinculados a la Comunicación $(30,4 \%)$ que campos temáticos transversales sobre Comunicación (18,5\%). Por otro lado, en cuanto a las asignaturas que sí son especializadas, el peso de la formación en Publicidad duplica al de la formación en Relaciones Públicas: la Publicidad se aborda en el 43,7\% de las asignaturas frente al $20,2 \%$ de asignaturas en las que se abordan las Relaciones Públicas.

En tercer lugar, otro objetivo específico de nuestra investigación fue identificar y cuantificar las actividades formativas contempladas en el marco de las metodologías docentes utilizadas en la formación universitaria presencial de grado sobre Publicidad y Relaciones Públicas en España. Una vez más, antes de ofrecer los resultados a este respecto conviene hacer una aclaración metodológica respecto al proceso de recogida de datos. En las guías docentes se codificó la información referida a las actividades empleadas en cada asignatura en su modalidad presencial, obviándose lo recogido en las adendas de la adaptación de la docencia a modalidad en remoto por reflejar una situación meramente coyuntural en el marco de la planificación docente de las asignaturas en los grados presenciales analizados. De cualquier modo, en algunos casos las guías no recogen información sobre actividades formativas y en otros casos no las cuantifican desde el punto de vista de las horas que corresponden a la docencia; ello por no hablar de los errores detectados en dicha cuantificación, en cuyo caso se ha optado por identificar las actividades formativas, pero no su duración en horas. Teniendo en cuenta estas incidencias, que, en todo caso, no invalidan el aporte de nuestra investigación debido al alto volumen de datos manejados, la tabla 9 evidencia que la clase teórica o magistral es la actividad formativa más utilizada en la docencia sobre Publicidad y Relaciones Públicas (supone 29.320 horas de docencia contabilizadas, un 40,0\% del total), seguida de la clase práctica (18.256 horas y 24,9\%), la elaboración de trabajos o resolución de casos (6.292 horas y 8,6\%) y la realización de seminarios o talleres ( 6.136 horas y $8,4 \%$ ). Ahora bien, las denominaciones que utilizan los distintos centros para cada actividad formativa es variable, de ahí la dificultad para la caracterización en todo caso, por lo que se ha creído interesante oponer el peso de la clase magistral, con una dimensión claramente teórica, al peso que supone la suma del total de actividades formativas con una dimensión más práctica, es decir, las tres últimas referidas anteriormente más la actividad de lecturas y/o visionados y la de debates y/o participación. Este bloque de dimensión práctica suma el $46,4 \%$ del total de la docencia, superior al mencionado 40,0\% de las clases teóricas o magistrales. Desagregando estos datos por tipo de centro en que se imparte la docencia, vemos que en los públicos la clase teórica tiene mayor peso 
frente al conjunto de actividades con dimensión práctica $(47,5 \%$ vs. $42,6 \%)$, mientras que en los privados sucede a la inversa ( $35,7 \%$ vs. $49,4 \%)$. Si abordamos los datos en función del tipo de asignatura, es en las obligatorias donde se utiliza menos la clase teórica $(37,8 \%$ frente al $48,1 \%$ del conjunto de actividades formativas prácticas), seguido por las optativas (42,1\% vs. 46,2\%). Por último estarían las asignaturas de formación básica, en las que predomina ligeramente la clase magistral (43,3\% vs. $42,8 \%)$. Terminando con los datos globales, el resto de las categorías tienen que ver con la monitorización del alumno: pruebas de evaluación, exposiciones orales y/o presentaciones públicas, y tutorías, que suman otro $10,4 \%$. Y finalmente hay otras actividades menos presentes, que suponen el restante $3,1 \%$.

Tabla 9. Tipo de actividad formativa por tipo de centro y asignatura

\begin{tabular}{|c|c|c|c|c|c|c|c|}
\hline \multirow{2}{*}{ Tipo de actividad } & \multicolumn{2}{|c|}{ Total } & \multicolumn{2}{|c|}{ Centro } & \multicolumn{3}{|c|}{ Asignatura } \\
\hline & Suma & $\%$ & Público & Privado & Obligatoria & F. básica & Optativa \\
\hline Clases teóricas & 29.321 & 40,0 & 14.676 & 14.645 & 15.110 & 7.263 & 6.948 \\
\hline Clases prácticas & 18.256 & 24,9 & 9.213 & 9.044 & 10.088 & 3.740 & 4.428 \\
\hline Trabajos y/o Casos & 6.292 & 8,6 & 2.223 & 4.069 & 3.208 & 1.123 & 1.961 \\
\hline Seminarios y/o Talleres & 6.136 & 8,4 & 1.888 & 4.248 & 3.917 & 1.519 & 701 \\
\hline Pruebas de evaluación & 3.511 & 4,8 & 1.406 & 2.105 & 2.042 & 857 & 613 \\
\hline Debates y/o Participación & 2.696 & 3,7 & 390 & 2.306 & 1.646 & 696 & 355 \\
\hline Tutorías & 2.540 & 3,5 & 1.353 & 1.187 & 1.475 & 558 & 507 \\
\hline Exposiciones orales y/o Presentaciones & 1.594 & 2,2 & 369 & 1.225 & 850 & 313 & 432 \\
\hline Otras & 1.562 & 2,1 & 358 & 1.204 & 911 & 442 & 209 \\
\hline Actividades complementarias & 710 & 1,0 & 349 & 361 & 384 & 159 & 167 \\
\hline Lecturas y/o Visionados & 651 & 0,9 & 48 & 603 & 368 & 104 & 179 \\
\hline
\end{tabular}

En cuarto y último lugar, identificar y cuantificar los sistemas de evaluación empleados en la formación universitaria presencial de grado sobre Publicidad y Relaciones Públicas en España fue otro de los objetivos específicos de nuestra investigación. Exponemos los datos a continuación, tras una breve aclaración en cuanto al proceso de recogida de datos. Para codificar las guías docentes, se siguió un criterio similar al utilizado en el caso de las actividades formativas en cuanto a las adendas para la adaptación de la docencia. Además, se recogió información de los sistemas de evaluación y su correspondiente ponderación en las convocatorias ordinarias o en evaluación continua y no en las convocatorias extraordinarias. Por otro lado, cuando la ponderación de los sistemas de evaluación se establece mediante horquillas de porcentajes muy amplios se ha considerado que ese dato no está disponible puesto que se entiende que la guía docente no aporta información específica y concreta sobre dicha ponderación. Finalmente, en caso de que en un mismo porcentaje se recogiesen varios sistemas de evaluación sin desglosar el peso de cada uno, se ha repartido dicho peso a partes iguales entre cada uno de esos sistemas de evaluación. Teniendo en cuenta todo ello y también el porcentaje que existe de guías docentes en el que no se recoge con precisión el peso de cada método de evaluación, el sistema de evaluación con más peso en el conjunto de las asignaturas (tabla 10) son las pruebas escritas, los tradicionales exámenes (de media suponen el 36,9\% de la calificación), seguidos de la evaluación mediante trabajos y/o proyectos (23,3\%) y, en tercer lugar, mediante prácticas $(20,0 \%)$. Ahora bien, como sucedía con las actividades formativas, la línea de separación entre esos dos últimos sistemas de evaluación es muy delgada ya que en cada centro de formación utiliza una terminología propia para cada sistema; por ello, a la hora de codificar cada guía docente, en caso de que en la misma no se utilizase ninguna de esas denominaciones sino otra similar se optó por registrarlo como prácticas cuando el sistema se componía de una diversidad de pruebas a lo largo del curso, normalmente de carácter individual, y trabajo cuando se trataba de proyectos de mayor duración en el curso, normalmente de naturaleza grupal. Sea como fuere, lo cierto es que la suma de estos sistemas de evaluación con una dimensión más práctica supera a la evaluación mediante pruebas escritas o exámenes, ligada más frecuentemente a conocimientos teóricos. Otros sistemas de evaluación mucho menos empleados en el total de la docencia son, por este orden: participación en el aula, exposiciones orales y/o presentaciones públicas, y exámenes orales; se recogieron también porcentajes muy reducidos para la evaluación mediante actividades complementarias, referidas a jornadas y conferencias fuera del horario de las asignaturas, así como a la categoría de otros, en la que incluyeron los casos marginales cuya descripción no pudiera incorporarse a ninguna de las anteriores categorías. En la tabla 10 se recogen las diferencias en función del tipo de centro de formación y el tipo de asignatura. Se observa que las pruebas escritas tienen algo más de relevancia en los centros privados que en los públicos (39,5\% de peso medio en la calificación frente a 33,2\%, respectivamente), los cuales dan un poco más de peso a la evaluación a través tanto de trabajos y/o proyectos como a través de prácticas. Según el tipo de asignatura, la evaluación mediante examen o prueba escrita supone un mayor porcentaje de media en las calificaciones de las asignaturas de formación básica (el $46,2 \%$ ) y bastante menos en las optativas (27,6\%); paralelamente, la importancia de la evaluación por proyectos o trabajos se eleva en las optativas $(28,7 \%)$, en las que también cobra más relevancia, aunque de forma limitada, la evaluación por participación o por exposiciones orales en el aula. 
Tabla 10. Sistemas de evaluación. Peso medio por tipo de centro y de asignatura

\begin{tabular}{|c|c|c|c|c|c|c|c|c|c|}
\hline & & $\begin{array}{l}\text { Prueba } \\
\text { escrita }\end{array}$ & $\begin{array}{c}\text { Prueba } \\
\text { oral }\end{array}$ & $\begin{array}{l}\text { Trabajo y/o } \\
\text { Proyecto }\end{array}$ & $\begin{array}{l}\text { Prácticas } \\
\text { y/o Casos }\end{array}$ & $\begin{array}{c}\text { Exposiciones } \\
\text { orales y/o } \\
\text { Presentaciones }\end{array}$ & Participación & $\begin{array}{c}\text { Actividades } \\
\text { complementarias }\end{array}$ & Otros \\
\hline Total & Peso medio & $36,9 \%$ & $0,5 \%$ & $23,3 \%$ & $20,0 \%$ & $2,4 \%$ & $3,3 \%$ & $0,1 \%$ & $0,5 \%$ \\
\hline \multirow{2}{*}{ Centro } & Público & $33,2 \%$ & $0,4 \%$ & $25,3 \%$ & $21,2 \%$ & $2,6 \%$ & $2,8 \%$ & $0,1 \%$ & $0,5 \%$ \\
\hline & No público & $39,5 \%$ & $0,5 \%$ & $22,0 \%$ & $19,2 \%$ & $2,3 \%$ & $3,6 \%$ & $0,0 \%$ & $0,5 \%$ \\
\hline \multirow{3}{*}{ Asignatura } & Obligatoria & $38,1 \%$ & $0,5 \%$ & $23,7 \%$ & $20,3 \%$ & $2,4 \%$ & $2,9 \%$ & $0,1 \%$ & $0,4 \%$ \\
\hline & F. básica & $46,2 \%$ & $0,5 \%$ & $15,8 \%$ & $19,7 \%$ & $1,8 \%$ & $2,9 \%$ & $0,1 \%$ & $0,6 \%$ \\
\hline & Optativa & $27,6 \%$ & $0,4 \%$ & $28,7 \%$ & $19,7 \%$ & $3,1 \%$ & $4,3 \%$ & $0,0 \%$ & $0,6 \%$ \\
\hline
\end{tabular}

\section{Conclusiones}

Cuando se cumplen 50 años de la incorporación de los estudios de Comunicación a la universidad española, la formación sobre Publicidad y Relaciones Públicas vive un momento de consolidación. Tras la destacada expansión de estos estudios durante la década de los noventa y los primeros años del actual siglo y tras los diferentes cambios normativos que han ido abriendo paso a las actuales titulaciones universitarias adaptadas a Bolonia, en la actualidad más del $40 \%$ de las universidades españolas oferta grados sobre Publicidad y Relaciones Públicas. La expansión económica y de los mercados de consumo a pesar de las crisis cíclicas del sistema financiero, el desarrollo del sistema mediático y el auge de la revolución digital o la buena aceptación social de estos estudios han afianzado su demanda. El ánimo de la investigación aquí presentada fue precisamente hacer balance de la situación mediante una descriptiva de los 41 grados universitarios presenciales sobre Publicidad y Relaciones Públicas en España a través del análisis de sus 1.815 guías docentes de asignaturas, para así conocer de manera actualizada cómo se caracteriza esa oferta formativa y qué y cómo se enseña en la misma.

Los resultados obtenidos permiten concluir, en primer lugar, el destacado papel que ya tiene la iniciativa privada en la formación universitaria presencial de grado sobre Publicidad y Relaciones Públicas en España, como ya se venía previendo en trabajos precedentes. De hecho, no es más que el reflejo del nacimiento progresivo de nuevas universidades privadas que pasan a ofertar estudios de Comunicación desde 1991, año en el que un real decreto abrió la puerta a estos nuevos centros de formación (García-Nieto; Davara-Rodríguez, 2020), promoviendo una "explosión" de los estudios sobre Comunicación en España (Martínez-Nicolás, 2020; Martínez-Nicolás; Saperas-Lapiedra; Carrasco-Campos, 2019) y consecuentemente una "expansión y descentralización de la docencia en Publicidad" (Méndiz-Noguero, 2000, p. 211). La sucesiva implantación de universidades privadas en diferentes puntos del territorio español, junto al florecimiento de centros adscritos tanto a universidades públicas como privadas, han provocado que ya sean en torno a 6 de cada 10 los grados de esta área que actualmente se imparten en centros de gestión privada, atraídos por la demanda social de estas titulaciones; cifra muy relevante si tenemos en cuenta que la gran mayoría de los grados universitarios en España se sigue impartiendo en universidades públicas (Baladrón-Pazos, 2018). Ello a pesar de que por número de alumnos las universidades públicas siempre hayan tenido una mayor relevancia o a pesar de que diferentes trabajos publicados concluyan que, más allá de la docencia, el liderazgo en la investigación sobre Publicidad y Relaciones Públicas es público; por ejemplo, menos del 15\% de las tesis doctorales de Publicidad defendidas entre 1976 y 2016 fueron presentadas en universidades privadas (Baladrón-Pazos; Manchado-Pérez; Correyero-Ruiz, 2019) y similar porcentaje es el de tesis sobre Relaciones Públicas entre 2005 y 2018 (Castillo-Esparcia; Carretón-Ballester; Pineda-Martínez, 2020). Por otra parte, lo más frecuente en la universidad española sigue siendo mantener la denominación y planteamiento tradicionales de las titulaciones conjuntas en Publicidad y Relaciones Públicas, aunque desde hace años las normativas nacionales abrieron la puerta a la diversificación de la oferta en sustitución del rígido catálogo de títulos que existía anteriormente.

En segundo lugar, respecto a los contenidos o campos temáticos en la formación universitaria presencial de grado sobre Publicidad y Relaciones Públicas en España, se concluye, por un lado, el destacado carácter generalista de estos estudios, en consonancia con el tipo de formación que corresponde a un grado en el actual sistema de ordenación de las enseñanzas universitarias. En cuanto a las asignaturas que se centran en contenidos especializados en Publicidad y en Relaciones Públicas, es claramente predominante la formación en Publicidad frente a la de Relaciones Públicas. En trabajos previos de aproximación histórica a la formación sobre Publicidad y Relaciones Públicas en España se recogen algunos datos que pueden explicar esta situación actual; por ejemplo, cuando las Relaciones Públicas se incorporaron a la universidad española en la recién inaugurada sección de Publicidad y Relaciones Públicas de la Universidad Complutense de Madrid se agrupaban 28 asignaturas, de las cuales 10 se dedicaban a Relaciones Públicas (García-Nieto; Davara-Rodríguez, 2020) y en esos orígenes tanto en ésta como en las otras dos universidades públicas pioneras, el número de asignaturas específicas de Relaciones Públicas era muy reducido (Méndiz-Noguero, 2000). Con independencia de esas razones históricas, los datos obtenidos en nuestra investigación en cierto modo corroboran lo concluido en la mayoría de las investigaciones publicadas, aunque hayan utilizado fuentes o metodologías de análisis diferentes. En este

Solo el 7,1\% de la docencia se lleva a cabo en inglés y el $2,1 \%$ es bilingüe 
sentido, Matilla, Hernández-Martínez y Compte-Pujol

(2018) señalaron que las asignaturas específicas de Publicidad suponen el $68,69 \%$ y las de Relaciones Públicas el 31,01\% sobre el total de asignaturas específicas de ambas áreas; y a conclusiones similares se llega en estu-

dios previos realizados por estos autores (cabe mencionar, excluyendo los centrados en el sistema universitario catalán, Matilla; Hernández-Martínez, 2012). Aunque con porcentajes diferentes, a similar conclusión llegaron Xifra (2007), Perlado-Lamo-de-Espinosa y Saavedra-Llamas (2017) (80\% vs. 20\%) o Castillo-Esparcia y Xifra (2006) (85\% vs. 15\%), entre otros. Se constata, pues, la prevalencia de la formación sobre Publicidad, si bien los datos de los diferentes estudios no son del todo comparables ya que en nuestro caso -como ya se indicó- se llega a dicha conclusión no con el análisis de los títulos de cada asignatura -como se hace en otros trabajos- sino tomando como referencia los temarios recogidas en las guías docentes. Incluso hay estudios (Flores-Mayorga; Roca-Correa, 2011) que, aunque con una cobertura de centros menor, casi equiparan el peso de la formación en Publicidad y en Relaciones Públicas (22\% vs. 20\% del total de asignaturas), lo cual evidencia el influjo del planteamiento metodológico a la hora de obtener unos u otros resultados. En cualquier caso, de acuerdo con nuestra investigación la Publicidad es también mayoritaria entre los campos temáticos especializados en Publicidad o en Relaciones Públicas con una mayor presencia en la formación analizada. De esos 10 primeros campos, solo 3 son de Relaciones Públicas. El campo temático más relevante es el que tiene que ver con la creatividad publicitaria y los procesos creativos, dato que corrobora las averiguaciones de estudios previos como el de Alonso-González (2008) y la propia tradición histórica de este campo en los estudios publicitarios (Méndiz-Noguero, 2000). Se trata, la creatividad, de un aspecto tradicionalmente central en la formación publicitaria frente a lo que sucede en los grados de Periodismo y Comunicación Audiovisual (Castelló-Martínez, 2020). El segundo más importante es el de la Publicidad y el Marketing digital, lo cual evidencia el esfuerzo que en ocasiones sí están haciendo los centros de formación para acomodar sus planes formativos a los perfiles y demandas actuales del mercado laboral; en este sentido, se constata un avance o mayor presencia de este campo que en estudios realizados hace unos años, aunque con distinto alcance y metodología (Castelló-Martínez, 2012).

En tercer lugar, se concluye que la influencia del llamado Plan Bolonia y todas las políticas y normativas a él vinculadas ha sido importante en la evolución hasta la actualidad de la formación universitaria presencial de grado sobre Publicidad y Relaciones Públicas en España. Por una parte, cabe destacar cómo la renovación de los planes de estudio para su adaptación a Bolonia ha asentado los itinerarios formativos con una duración en créditos de las asignaturas cada vez menor, dado que casi 8 de cada 10 asignaturas tienen un peso de 6 créditos y el resto suponen mayoritariamente un menor número de créditos, frente a las generalizadas asignaturas anuales de las licenciaturas universitarias anteriores incluso a la normativa de 1987. Similar peso en créditos se recoge en un estudio previo también basado en el análisis de las guías docentes, aunque focalizado en un campo publicitario más específico (Gómez-Nieto; Tapia-Frade, 2017). Por otra parte, respecto al cómo se enseña, se puede concluir que la transformación metodológica que proponía el Plan Bolonia también ha dejado poso en la forma de enseñar en los grados presenciales sobre Publicidad y Relaciones Públicas en España. Así, actualmente en las metodologías docentes se integran con frecuencia actividades formativas con dimensión práctica y basadas en una mayor interacción entre profesor y estudiante, frente a las clases teóricas o magistrales; de hecho, solo 4 de cada 10 horas se destinan a clases teóricas, dato contrapuesto al concluido en otros trabajos anteriores más restringidos como el de Fondevila-Gascón et al. (2015), que estimaba en un 90\% el peso de la formación teórica, si bien analizando tan solo la formación en las universidades barcelonesas. Esto nos puede llevar a concluir que clases prácticas, seminarios, talleres, análisis de casos, debates, participación, etc., son conceptos que se han incorporado de forma extensa a la formación presencial de grado sobre Publicidad y Relaciones Públicas en España, pese a que no se haya alcanzado en su totalidad la renovación metodológica que preconizaba Bolonia. Asimismo, ese planteamiento parece trasladarse también a la hora de evaluar el rendimiento del estudiante; no en vano los sistemas de evaluación basados en trabajos o proyectos y en prácticas suponen conjuntamente un porcentaje similar al que las actividades formativas prácticas representan en el marco de las metodologías docentes de las asignaturas, y en todo caso superior al de las pruebas escritas o exámenes. En el estudio anteriormente referenciado (Gómez-Nieto; Tapia-Frade, 2017), centrado en el caso de las asignaturas de teoría de la publicidad, también se concluía el importante papel de trabajos y prácticas en la evaluación del alumno, incluso a pesar de analizarse asignaturas tradicionalmente consideradas teóricas. Ahora bien, la convergencia europea no parece haber conducido a una extendida internacionalización en la formación presencial de grado sobre Publicidad y Relaciones Públicas en las universidades españolas (mención aparte de los planes que se pudieran impartir parcialmente en otros países), al menos respecto al idioma en que se imparte, que fue una de las variables analizadas en nuestra investigación. La docencia en inglés o bilingüe es en general minoritaria dado que, según lo consignado en las guías docentes, aproximadamente 9 de cada 10 asignaturas se imparten en español o cualquier otra lengua cooficial, a pesar de que la tendencia en los últimos años en el panorama universitario español haya sido a una mayor implantación de grados bilingües, que no parecen haber calado intensamente en la formación sobre Publicidad y Relaciones Públicas analizada. En todo caso, son, con diferencia, los centros públicos los que menos ofertan docencia en inglés o bilingüe, prácticamente po-
Los sistemas de evaluación de tipo práctico superan a las pruebas escritas o exámenes sobre conocimientos teóricos 
dríamos decir que queda circunscrita a las asignaturas de idioma, mientras que en los centros privados es una práctica algo más habitual.

La investigación realizada ha permitido obtener una descripción actual de la formación universitaria presencial de grado sobre Publicidad y Relaciones Públicas en España, no solo en cuanto a aspectos formales sino también respecto a otros de mayor calado vinculados a los contenidos abordados, las actividades formativas utilizadas y los sistemas de evaluación empleados. Una de las novedades frente a gran parte de los trabajos precedentes -referenciados al comienzo de este artículo y consistentes en el análisis de los planes de estudio- ha sido basarse en el estudio de las guías docentes de las asignaturas, el documento oficial que más fielmente ha de reflejar cómo se lleva a cabo la docencia. De hecho, no son muy numerosos los estudios publicados que se fundamentan en el análisis de las guías docentes como vía para obtener conocimiento acerca de la formación universitaria presencial sobre Publicidad y Relaciones Públicas en España (por ejemplo: Fanjul-Peyró; Pérez-Serrano; Cabezuelo-Lorenzo, 2010; Fondevila-Gascón et al., 2015; Gómez-Nieto; Tapia-Frade, 2017). Ahora bien, pese a la aportación de la investigación realizada, es preciso mencionar algunas de sus limitaciones. Por un lado, la formación sobre Publicidad y Relaciones Públicas es un ente dinámico -como lo son las propias guías docentes, renovadas cada curso académico- por lo que sería de indudable interés replicar la investigación en sucesivos cursos académicos para poder observar la evolución en el tiempo. En nuestro estudio se aporta una instantánea insuficiente para entender la realidad cambiante de esa formación si no se revisa periódicamente. Por otro lado, no han formado parte de la investigación realizada cuestiones de indudable relevancia y que también se recogen en las guías docentes, como las competencias o los resultados de aprendizaje; tal y como se explicó anteriormente, ello fue debido tanto a la necesidad de acotar los objetivos de la investigación como a la compleja categorización de esas variables y por tanto la necesidad de ampliar el planteamiento metodológico utilizado en nuestra investigación para llevar a cabo su análisis con rigor. Sin lugar a dudas, éstas y otras cuestiones no abordadas en la investigación aquí presentada abren la puerta a posteriores análisis complementarios, que ayuden en mayor grado a conocer la realidad actual y las tendencias en la formación universitaria presencial de grado sobre Publicidad y Relaciones Públicas en España, tras cumplirse 50 años de la incorporación de los estudios de Comunicación a la universidad española.

\author{
La transformación metodológica que \\ proponía el Plan Bolonia ha dejado poso \\ en la forma de enseñar en los grados so- \\ bre Publicidad y Relaciones Públicas
}

\section{Referencias}

Alegre-Rodríguez, Isam (2012). La enseñanza de la creatividad en los estudios de Publicidad de las universidades españolas. Un análisis de los temarios de las asignaturas de Estrategia creativa, Redacción creativa, Dirección de arte y Creatividad Publicitaria. Réplica del estudio de Stuhlfaut y Berman (2009) en Estados Unidos. Barcelona: Universitat Autònoma de Barcelona.

https://ddd.uab.cat/record/103296

Alemany-Martínez, Dolores (2020). "La disciplina Documentación informativa en los planes de estudio de la licenciatura de Publicidad y Relaciones Públicas". Cuadernos de documentación multimedia. I Congreso universitario de ciencias de la documentación. Teoría, historia y metodología de la documentación en España (1975-2000), v. 10, pp. 185-191. https://revistas.ucm.es/index.php/CDMU/article/view/68836

Almansa-Martínez, Ana; Moreno-Cabanillas, Andrea (2021). "Historia y evolución de las relaciones públicas". En: Romero-Rodríguez, Luis M.; Fernández-Camacho, M. Carmen (coords.). Introducción a las Relaciones públicas. Madrid: McGraw-Hill, pp. 15-36. ISBN: 9788448624583

Alonso-González, Carmen-María (2004). "La creatividad publicitaria en la universidad: reflexiones para la profundización en el ámbito de la docencia". Creatividad y sociedad: Revista de la Asociación para la Creatividad, n. 6, pp. 47-60. http://creatividadysociedad.com/wp-content/uploads/2019/10/revista-CS-6.pdf

Alonso-González, Carmen-María (2008). "La creatividad publicitaria en la universidad española”. Comunicación y pluralismo, n. 6, pp. 215-258.

https://doi.org/10.36576/summa.29157

Aneca (2005). Libro blanco de los títulos de grado en Comunicación. http://www.aneca.es/var/media/150336/libroblanco_comunicacion_def.pdf

Baladrón-Pazos, Antonio-José (2018). "Evolución y retos de los estudios de publicidad en la universidad española". Rihumso, n. 14, pp. 47-68.

https://rihumso.unlam.edu.ar/index.php/humanidades/article/view/142

Baladrón-Pazos, Antonio-José; Manchado-Pérez, Benjamín; Correyero-Ruiz, Beatriz (2017). "Estudio bibliométrico sobre la investigación en publicidad en España: temáticas, investigadores, redes y centros de producción”. Revista española de documentación científica, v. 40, n. 2.

https://doi.org/10.3989/redc.2017.2.1411 
Baladrón-Pazos, Antonio-José; Manchado-Pérez, Benjamín; Correyero-Ruiz, Beatriz (2019). “La investigación sobre publicidad en la universidad. Características y temáticas de las tesis doctorales (1976-2016)". Revista latina de comunicación social, n. 74, pp. 767-785.

https://doi.org/10.4185/RLCS-2019-1356

Baños-González, Miguel; Martínez-Gallego, Francesc-Andreu; Papí-Gálvez, Natalia (2021). La formación de investigadores en Comunicación. Situación actual y desafíos. Salamanca: Comunicación Social, Ediciones y Publicaciones. ISBN: 978841760043

Barjau-Rico, Santi (2002). “Los inicios del pensamiento publicitario: Pere Prat Gaballí, Rafael Borí y el Publi Club. La teoría y la práctica de la publicidad racional en Cataluña entre 1915 y 1935 ". Publifilia. Revista de culturas publicitarias, n. 6, pp. 49-64.

https://publicacions.iec.cat/repository/pdf/00000062/00000023.pdf

Beneyto-Pérez, Juan (1957). Mass communications: un panorama de los medios de información en la sociedad moderna. Madrid: Instituto de Estudios Políticos.

Caldevilla-Domínguez, David; Barrientos-Báez, Almudena; Fombona-Cadavieco, Javier (2020). "Evolución de las Relaciones públicas en España. Artículo de revisión”. El profesional de la información, v. 29, n. 3.

https://doi.org/10.3145/epi.2020.may.05

Castelló-Martínez, Araceli (2012). “El estudio de la comunicación publicitaria online en el Grado en Publicidad y Relaciones Públicas". Questiones publicitarias, n. 17.

https://doi.org/10.5565/rev/qp.51

Castelló-Martínez, Araceli (2020). "Las asignaturas de creatividad y estrategia en los grados en Comunicación en España”. Revista latina de comunicación social, n. 77, pp. 143-178.

https://doi.org/10.4185/RLCS-2020-1453

Castelló-Martínez, Araceli; Tur-Viñes, Victoria (2019). “La competencia creativa en la formación universitaria. El caso de Publicidad y RR.PP.”. En: Roig-Vila, Rosabel; Antolí-Martínez, Jordi; Lledó-Carreres, Asunción; Pellín-Buades, Neus (coords.). Redes de investigación e innovación en docencia universitaria. Alicante: Universidad de Alicante, pp. 43-56. ISBN: 9788409071869

Castillo-Esparcia, Antonio; Carretón-Ballester, Carmen; Pineda-Martínez, Paula (2020). "Investigación en Relaciones Públicas en España". Profesional de la información, v. 29, n. 3, e290330.

https://doi.org/10.3145/epi.2020.may.30

Castillo-Esparcia, Antonio; Xifra, Jordi (2006). “Investigación bibliométrica de las tesis doctorales españolas sobre Relaciones Públicas”. Análisi. Quaderns de comunicació y cultura, n. 34, pp. 141-161.

https://riuma.uma.es/xmlui/bitstream/handle/10630/4852/tesis\%20doctorales\%20analisi.pdf

Corbacho-Valencia, Juan-Manuel (2013). "El protocolo en la docencia universitaria: la materia de Relaciones Públicas y Protocolo en el marco de la adaptación al Espacio Europeo de Educación Superior". Estudios sobre el mensaje periodístico, v. 19, n. 1, pp. 212-128.

https://doi.org/10.5209/rev_ESMP.2013.v19.42017

Cuenca-Fontbona, Joan; Compte-Pujol, Marc; Matilla, Kathy; Hernández-Martínez, Salvador (2017). “Un análisis de los masters universitarios españoles especializados en Relaciones Públicas y Comunicación Corporativa (curso 2016-2017) desde la perspectiva de las Relaciones Públicas". Obra digital. Revista de comunicación, n. 13, pp. 37-57.

https://doi.org/10.25029/od.2017.156.13

Declaración de Bolonia (1999). Joint declaration of the European Ministers of Education.

http://ehea.info/Upload/document/ministerial_declarations/1999_Bologna_Declaration_English_553028.pdf

Declaración de la Sorbona (1998). Joint declaration on harmonisation of the architecture of the European higher education system.

http://ehea.info/media.ehea.info/file/1998_Sorbonne/61/2/1998_Sorbonne_Declaration_English_552612.pdf

Eguizábal-Maza, Raúl (1998). Historia de la publicidad. Madrid: Editorial Eresma. ISBN: 9788482111604

España (1964). “Ley 61/1964, de 11 de junio, por la que se aprueba el Estatuto de la Publicidad”. BOE, n. 143, 15 junio, pp. 7804-7808.

https://www.boe.es/buscar/doc.php?id=BOE-A-1964-9400

España (1970). “Ley 14/1970, de 4 de agosto, general de educación y financiamiento de la reforma educativa". BOE, n. 187,6 agosto, pp. 12525-12546.

https://www.boe.es/buscar/doc.php?id=BOE-A-1970-852 
España (1971). “Decreto 2070/1971, de 13 de agosto, por el que se regulan los estudios de Periodismo y demás medios de comunicación social en la Universidad". BOE, n. 220, 14 septiembre, pp. 14944-14945.

https://www.boe.es/boe/dias/1971/09/14/pdfs/A14944-14945.pdf

España (1987). "Real decreto 1497/1987, de 27 de noviembre, por el que se establecen directrices generales comunes de los planes de estudio de los títulos universitarios de carácter oficial y validez en todo el territorio nacional". BOE, n. 298, 14 diciembre, pp. 36639-36643.

https://www.boe.es/buscar/doc.php?id=BOE-A-1987-27707

España (2001). “Ley orgánica 6/2001, de 21 de diciembre, de Universidades”. BOE, n. 307, 24 diciembre, pp. 4940049425.

https://www.boe.es/eli/es/lo/2001/12/21/6

España (2007). "Real decreto 1393/2007, de 29 de octubre, por el que se establece la ordenación de las enseñanzas universitarias oficiales". BOE, n. 260, 30 octubre, pp. 44037-44048.

https://www.boe.es/buscar/act.php?id=BOE-A-2007-18770

Estanyol-i-Casals, Elisenda (2012). "La enseñanza de la creatividad aplicada en relaciones públicas, en el marco de los grados adaptados al EEES". En: Actas del III Congreso internacional de la Asociación Española de Investigación de la Comunicación. Comunicación y riesgo. Tarragona: Universitat Rovira i Virgili. ISBN: 9788461556786

Fanjul-Peyró, Carlos; Pérez-Serrano, María-José; Cabezuelo-Lorenzo, Francisco (2010). "La guía docente como herramienta activa en la praxis didáctica de materias de Publicidad y RR.PP. adaptadas al EEES". @tic. Revista d'innovació educativa, n. 4, pp. 82-85.

https://doi.org/10.7203/attic. 4.173

Flores-Mayorga, Marco-Tulio; Roca-Correa, David (2011). “La enseñanza interdisciplinaria de las Relaciones Públicas en las universidades de España y México: un estudio exploratorio”. Correspondencias \& análisis, n. 1, pp. 83-99.

https://doi.org/10.24265/cian.2011.n1.06

Fondevila-Gascón, Joan; Santana-López, Eva; Rom-Rodríguez, Josep; Feliu-Roé, Lluís (2015). “Bases educativas de los planes de estudio del Grado de Publicidad y Relaciones Públicas en Cataluña”. Sphera pública, n. 15, pp. 117-132. http://sphera.ucam.edu/index.php/sphera-01/article/view/242

García-Nieto, María-Teresa; Davara-Rodríguez, Francisco-Javier (2020). “La génesis de las facultades españolas de Ciencias de la Información: del Periodismo y de las Relaciones Públicas". Aportes. Revista de historia contemporánea, v. 35, n. 103 , pp. 35-68.

https://revistaaportes.com/index.php/aportes/article/view/528/297

Gómez-Nieto, Begoña; Tapia-Frade, Alejandro (2017). "La enseñanza de la publicidad a través de la guía docente: el caso de la asignatura Teoría general de la publicidad". Revista complutense de educación, v. 28, n. 2, pp. $391-407$. https://doi.org/10.5209/rev_rced.2017.v28.n2.49401

Haug, Guy-Eugène (2015). Grados y másteres en España y el Espacio Europeo de Educación Superior (EEES). Madrid: CRUE. ISBN: 8460821656.

https://redined.mecd.gob.es/xmlui/handle/11162/120406

Hernández-Martínez, Salvador; Losada-Díaz, José-Carlos; Matilla, Kathy (2009). “Las relaciones públicas y la comunicación corporativa en la oferta universitaria del posgrado del Estado Español. Análisis sistemático y proyectivo y una iniciativa de observatorio del estado de la situación por parte de una asociación profesional". Razón y palabra, n. 70.

http://www.razonypalabra.org.mx/Articulo\%205\%20R\%20y\%20PPostgrado\%20en\%20RRPPSHernandez.doc_\%20 JCLosada.doc_\%20KMatilla_19.07.09.pdf

López-Berna, Sonia (2014). La publicidad en España tras la convergencia al Espacio europeo de educación superior: Estudio de la formación, regulación e institucionalización de un sector profesional. Tesis doctoral. Universidad de Alicante. https://rua.ua.es/dspace/bitstream/10045/86331/1/tesis_sonia_lopez_belda.pdf

López-Berna, Sonia; Papí-Gálvez, Natalia; Martín-Llaguno, Marta (2016). “La revisión de los grados universitarios: valoración de la convergencia europea del Grado en Publicidad y Relaciones Públicas en España”. Doxa comunicación, n. 23, pp. 47-71.

https://doi.org/10.31921/doxacom.n23a2

Magallón, Sara (2004). “La educación universitaria de las Relaciones Públicas en España”. En: Arceo-Vacas, José-Luis. Las Relaciones Públicas en España. Madrid: McGraw Hill Interamericana de España, pp. 375-388. ISBN: 8448141830

Martínez-Nicolás, Manuel (2020). "La investigación sobre Comunicación en España (1985-2015). Contexto institucional, comunidad académica y producción científica”. Revista latina de comunicación social, n. 75, pp. 383-414.

https://doi.org/10.4185/rlcs-2020-1432 
Martínez-Nicolás, Manuel; Saperas-Lapiedra, Enric; Carrasco-Campos, Ángel (2019). “La investigación sobre Comunicación en España en los últimos 25 años (1990-2014). Objetos de estudio y métodos aplicados en los trabajos publicados en revistas españolas especializadas". Empiria. Revista de metodología de ciencias sociales, n. 42, pp. 37-69.

https://doi.org/10.5944/empiria.42.2019.23250

Matilla, Kathy; Hernández-Martínez, Salvador (2012). “Bolonia Km 0: los estudios universitarios en Relaciones Públicas del estado español en el curso 2009-2010”. En: Ordeix-Rigo, Enric; Rom-Rodríguez, Josep A. La innovació en relacions publiques: V Congrés internacioanl d'investigació i relacions públiques. Barcelona: Universitat Ramon Llull, pp. 315-330. ISBN: 9788493695934

Matilla, Kathy; Hernández-Martínez, Salvador; Compte-Pujol, Marc (2016). “Relaciones Públicas y Comunicación Corporativa en los grados universitarios catalanes en el curso académico 2015-2016". Revista internacional de Relaciones Públicas, v. 6, n. 11, pp. 213-234.

https://doi.org/10.5783/rirp-11-2016-11-213-234

Matilla, Kathy; Hernández-Martínez, Salvador; Compte-Pujol, Marc (2018). “Modelos profesionales y grados universitarios de Publicidad y Relaciones Públicas en España desde la perspectiva de las Relaciones Públicas (2017-2018). Communication papers: Media literacy and gender studies, v. 7, n. 15, pp. 91-104.

https://doi.org/10.33115/udg_bib/cp.v7i15.22185

Matilla, Kathy; Hernández-Martínez, Salvador; Losada-Díaz, José-Carlos (2010). "La oferta formativa de Relaciones Públicas en los nuevos grados universitarios en España (2009-2010)”. Pangea, v. 1, n. 1, pp. 124-159.

https://revistapangea.org/index.php/revista/article/view/17

Méndiz-Noguero, Alfonso (2000). “Orígenes, evolución y desafíos actuales de la docencia publicitaria en España”. Comunicación y sociedad, v. 13, n. 2, pp. 181-225.

https://dadun.unav.edu/bitstream/10171/7913/1/20100226112514.pdf

Míguez-González, María-Isabel; Baamonde-Silva, Xosé-Manuel; Corbacho-Valencia, Juan-Manuel (2014). "A bibliographic study of Public Relations in Spanish media and communication journals, 2000-2012". Public relations review, v. 40, n. 5, pp. 818-828.

https://doi.org/10.1016/j.pubrev.2014.08.002

Míguez-González, María-Isabel; Costa-Sánchez, Carmen (2019). “Tendencias de investigación sobre comunicación organizacional: la autoría española en revistas indexadas (2014-2018)”. El profesional de la información, v. 28 , n. 5. https://doi.org/10.3145/epi.2019.sep.10

Ministerio de Universidades (2021). Estadística de universidades, centros y titulaciones. Curso 2020-2021.

http://estadisticas.mecd.gob.es/EducaDynPx/educabase/index.htm?type=pcaxis\&path=/Universitaria/EUCT/Serie// Estructura/\&file=pcaxis

Murciano-Martínez, Marcial (2010). "La transformación de los estudios de comunicación en España”. Diálogos de la comunicación, n. 79, pp. 1-10.

https://core.ac.uk/download/pdf/18417674.pdf

Noguero-Grau, Antonio (1994). “Historia de las Relaciones Públicas en España: 1954-1990”. Revista universitaria de publicidad y relaciones públicas, n. 1, pp. 67-90.

Orbea-Mira, Jesús; Tur-Viñes, Victoria; Fernández-Poyatos, María-Dolores (2006a). “Enseñar estrategia de comunicación publicitaria en el contexto europeo de educación superior". En: Iglesias-Martínez, Marcos; Lapeña-Pérez, Cristina; Pastor-Verdú, Francisco (eds.). IV Jornadas de redes de investigación en docencia universitaria: la construcción colegiada del modelo docente universitario del siglo XXI. Alicante: Universidad de Alicante. ISBN: 8469093118

Orbea-Mira, Jesús; Tur-Viñes, Victoria; Fernández-Poyatos, María-Dolores (2006b). “Aportaciones al diseño curricular: guías docentes de las asignaturas: aproximación a la docencia de la Creatividad Publicitaria en el contexto del Espacio Europeo de Educación Superior". En: Martínez-Ruiz, María-Ángeles; Carrasco-Embuena, Vicente (eds.). Redes de investigación docente en el espacio europeo de educación superior. Vol. I: La multidimensionalidad de la educación universitaria. Alcoy: Universidad de Alicante/Marfil, pp. 267-290. ISBN: 842681266 X

Pena-Rodríguez, Alberto; Rúas-Araújo, José (2003). “A formación universitaria dos publicitarios e relacións públicas en Galicia". Estudios de comunicación, n. 2, pp. 61-67.

http://consellodacultura.gal/mediateca/extras/CCG_2003_Estudios-de-Comunicacion-no-2-2003.pdf

Perlado-Lamo-de-Espinosa, Marta; Saavedra-Llamas, Marta (eds.) (2017). Los estudios universitarios especializados en Comunicación en España. Barcelona: UOC. ISBN: 9788491167013

Perlado-Lamo-de-Espinosa, Marta; Saavedra-Llamas, Marta; Rubio-Romero, Juana (2016). “La formación universitaria en España dentro del ámbito de la comunicación corporativa”. En: Perlado-Lamo-de-Espinosa, Marta; Cachán-Alcolea, Carlos (coords.) Competencias y perfiles profesionales en el ámbito de la comunicación. Madrid: Dykinson, pp. 263-274. ISBN: 9788490858523 
Prat-Gaballí, Pedro (1917). Una nueva técnica. La publicidad científica. Barcelona: Cámara de Comercio y Navegación de Barcelona.

Quintas-Froufe, Eva (2011). “El legado del hombre que se tomó la publicidad en serio: Pedro Prat Gaballí. Aproximación a sus contribuciones teóricas y profesionales". Área abierta, n. 30.

https://doi.org/10.5209/rev_arab.2011.n30.37838

Ramírez-Alvarado, María-del-Mar; Clemente-Mediavilla, Jorge (coords.) (2020). Docencia e investigación en comunicación en España. Salamanca: Comunicación Social Ediciones y Publicaciones. ISBN: 9788417600297

Ramos-Serrano, Marina; Muñiz-Velázquez, José-Antonio (2018). “Los siete grandes retos de 'enseñar' creatividad publicitaria en la Universidad”. En: García-García, Francisco; Tur-Viñes, Victoria; Arroyo-Almaraz, Isidoro; Rodrigo-Martí, Luis (coords.). Creatividad en publicidad: del impacto al comparto. Madrid: Dikynson, pp. 17-36. ISBN: 9788491485674

Repiso, Rafael; Berlanga-Fernández, Inmaculada; Said-Hung, Elías; Castillo-Esparcia, Antonio (2020). "Titularidades y cátedras en Comunicación en España (2000-2019). Distribución, ritmos de promoción, transferencia entre universidades y endogamia". Profesional de la información, v. 29, n. 4, e290422.

https://doi.org/10.3145/epi.2020.jul.22

Rey-Fuentes, Juan (2009). “Veinte años de investigación y docencia publicitarias en Sevilla”. Admira, n. 1, pp. $227-238$. https://doi.org/10.12795/admira.2009.01.14

Romero-Rodríguez, Luis M.; Fernández-Camacho, Carmen (coords.) (2021). Introducción a las Relaciones Públicas. Madrid: McGraw-Hill, pp. 15-36. ISBN: 9788448624583

Seoane-Pérez, Francisco; Martínez-Nicolás, Manuel; Vicente-Mariño, Miguel (2020). "Fuga de talento en la investigación española sobre Comunicación: percepciones de los investigadores españoles en el extranjero". Profesional de la información, v. 29, n. 4, e290433.

https://doi.org/10.3145/epi.2020.jul.33

Sierra-Sánchez, Javier (2014). “Análisis de la situación laboral del profesorado de Ciencias de la Comunicación en España". Historia y comunicación social, n. 19, pp. 759-778.

https://doi.org/10.5209/rev_hics.2014.v19.45064

Torres-Romay, Emma (2010). “Enseñanza universitaria de la comunicación estratégica en España.Análisis de la repercusión del proceso de adaptación al Espacio Europeo de Educación Superior en la enseñanza de estrategias". Signo y pensamiento, v. 29, n. 56, pp. 304-327.

http://www.scielo.org.co/scielo.php?script=sci_arttext\&pid=S0120-48232010000100018

Tur-Viñes, Victoria (2006). "La creatividad publicitaria en el Espacio Europeo de Educación Superior". En: Rom, Josep; Sabaté, Joan (eds.). Revisemos las teorías de la creatividad. III Simposium de profesores universitarios de creatividad publicitaria. Trípodos, n. 5, pp. 153-160. Barcelona: Universitat Ramon Llull.

https://rua.ua.es/dspace/bitstream/10045/4410/3/Tur_MaqCong05.pdf

Vázquez-Gestal, Montserrat (2001). “Creatividad en la licenciatura de Publicidad y Relaciones Públicas". En: Romo-Santos, Manuela; Sanz-Lobo, Estefanía (coords.). Creatividad y currículum universitario. Madrid: Universidad Autónoma de Madrid, pp. 117-122. ISBN: 8474777917

Vigil-y-Vázquez, Manuel (1987). El periodismo enseñado. De la escuela de 'El debate' a Ciencias de la información. Barcelona: Mitre. ISBN: 8476520220

Vivar-Zurita, Hipólito; García-García, Alberto; Abuín-Vences, Natalia; Vinader-Segura, Raquel (2010). “Análisis de los estudios de comunicación en España frente al resto del Espacio Europeo de Educación Superior". En: Actas II Congreso internacional AE-IC. Comunicación y desarrollo en la era digital. Madrid: AE-IC; Universidad de Málaga.

http://www.ae-ic.org/malaga2010/upload/ok/307.pdf

Xifra, Jordi (2006). “Lucient Matrat y la consolidación de las Relaciones Públicas en Europa”. Historia y comunicación social, n. 11, pp. 229-240.

https://revistas.ucm.es/index.php/HICS/article/view/HICS0606110229A/19184

Xifra, Jordi (2007) “Undergraduate public relations education in Spain: endangered species?”. Public relations review, v. 33, n. 2, pp. 206-213.

https://doi.org/10.1016/j.pubrev.2007.02.006

Xifra, Jordi; Castillo-Esparcia, Antonio (2006). "Forty years of doctoral public relations research in Spain: A quantitative study of dissertation contribution to theory development". Public relations review, v. 32, n. 3, pp. 302-308.

https://doi.org/10.1016/j.pubrev.2006.05.004 